\title{
Resting motor threshold in the course of hand motor recovery after stroke: a systematic review
}

\author{
Jitka Veldema ${ }^{1 *}$, Dennis Alexander Nowak ${ }^{2}$ and Alireza Gharabaghi ${ }^{1}$
}

\begin{abstract}
Background: Resting motor threshold is an objective measure of cortical excitability. Numerous studies indicate that the success of motor recovery after stroke is significantly determined by the direction and extent of cortical excitability changes. A better understanding of this topic (particularly with regard to the level of motor impairment and the contribution of either cortical hemisphere) may contribute to the development of effective therapeutical strategies in this cohort.
\end{abstract}

Objectives: This systematic review collects and analyses the available evidence on resting motor threshold and hand motor recovery in stroke patients.

Methods: PubMed was searched from its inception through to 31/10/2020 on studies investigating resting motor threshold of the affected and/or the non-affected hemisphere and motor function of the affected hand in stroke cohorts.

Results: Overall, 92 appropriate studies (including 1978 stroke patients and 377 healthy controls) were identified. The analysis of the data indicates that severe hand impairment is associated with suppressed cortical excitability within both hemispheres and with great between-hemispheric imbalance of cortical excitability. Favorable motor recovery is associated with an increase of ipsilesional motor cortex excitability and reduction of between-hemispheric imbalance. The direction of change of contralesional motor cortex excitability depends on the amount of hand motor impairment. Severely disabled patients show an increase of contralesional motor cortex excitability during motor recovery. In contrast, recovery of moderate to mild hand motor impairment is associated with a decrease of contralesional motor cortex excitability.

Conclusions: This data encourages a differential use of rehabilitation strategies to modulate cortical excitability. Facilitation of the ipsilesional hemisphere may support recovery in general, whereas facilitation and inhibition of the contralesional hemisphere may enhance recovery in severe and less severely impaired patients, respectively.

Keywords: Resting motor threshold, Hand motor recovery, Stroke

\footnotetext{
*Correspondence: jitka.veldema@klinikum.uni-tuebingen.de ${ }^{1}$ Institute for Neuromodulation and Neurotechnology, Department of Neurosurgery and Neurotechnology, University Hospital and University of Tübingen, Otfried-Mueller-Str.45, 72076 Tübingen, Germany Full list of author information is available at the end of the article
}

\section{Introduction}

Stroke is the leading cause of long-term disability in adults world-wide [1]. In consequence, rehabilitation and optimized care of stroke survivors is of high socio-economic priority. Motor impairment is the most common clinical deficit after stroke [1] and its recovery usually remains incomplete. Six months after the original author(s) and the source, provide a link to the Creative Commons licence, and indicate if changes were made. The images or other third party material in this article are included in the article's Creative Commons licence, unless indicated otherwise in a credit line to the material. If material is not included in the article's Creative Commons licence and your intended use is not permitted by statutory regulation or exceeds the permitted use, you will need to obtain permission directly from the copyright holder. To view a copy of this licence, visit http://creativecommons.org/licenses/by/4.0/. The Creative Commons Public Domain Dedication waiver (http://creativeco mmons.org/publicdomain/zero/1.0/) applies to the data made available in this article, unless otherwise stated in a credit line to the data. 
cerebro-vascular incident 60 to 70 percent of stroke survivors suffer from motor impairment of one hand which significantly impacts disability and activities of daily living [2,3]. Up to now, tens of studies have shown that motor recovery after stroke is accompanied by reorganization of the functional network architecture within both the lesioned and the non-lesioned hemisphere [4, 5]. Nevertheless, the mechanism underlying recovery of motor function after a focal lesion is still not sufficiently understood.

Transcranial magnetic stimulation (TMS) is a neurophysiological method often used to probe neural processing related to hand motor function/recovery after stroke. A comprehensive analysis of these data may help to foster our understanding of the neurophysiological changes in cortical excitability accompanying motor recovery and, at the same time, may contribute to optimize stroke rehabilitation. For this reason, we performed a review on the relationship of changes in corticospinal excitability within the ipsi- and contralesional hemisphere (as measured by TMS) and the functional outcome of the affected hand after stroke. This review summarizes current data on resting motor threshold and hand motor function over the course of recovery after stroke and compares these data with the data of healthy subjects. Following issues need to be clarified: (1) Is the cortical excitability of the ipsi- and the contralesional hemisphere in stroke patients higher or lower in comparison to a healthy brain? (2) Is the between-hemispheric balance of cortical excitability in stroke subjects shifted toward the contra- or ipsilesional hemisphere? (3) Is there a relationship between the level of cortical excitability within either hemisphere and the between-hemispheric imbalance? (4) Is there a relationship between the level of cortical excitability within either hemisphere and/or the between-hemispheric imbalances, and the motor function/motor recovery of the affected hand?

\section{Neural plasticity following stroke}

A focal brain lesion causes disturbance of functional and structural architecture within both the ipsilesional and contralesional hemisphere $[4,5]$. Motor recovery results from the reorganization of neural interconnection within intact neuron pools, and causes alterations of movementrelated neural activity within perilesional and more distant brain areas $[4,5]$. This process is thought to compensate and adjust functional brain capacities to the new situation. "Adaptive/positive plasticity" means reorganization within neural tissue to optimize neural resources for recovery of function. However, such brain plasticity is not always "adaptive/positive". The idea of "maladaptive/ negative plasticity", which may hamper motor recovery after stroke, is based on the theory of interhemispheric rivalry $[6,7]$. In a healthy brain, neural activity in the motor areas of both hemispheres is functionally coupled and equally balanced in terms of mutual inhibitory control. An active movement of a hand is associated with an enhanced neural activity in contralateral motor areas and increased inhibitory influence toward homologous areas of the ipsilateral hemisphere $[8,9]$. In stroke patients, a shift of the between-hemispheric balance detrimental to the affected hemisphere can be observed. Several fMRI and PET studies have shown that during an active movement of the affected hand there is increased neural activity within motor areas of both the lesioned and the non-lesioned hemisphere and describe a link to hand motor disability [10-13]. Patients with a favorable functional outcome show lateralized activation within the contralateral hemisphere (comparably to healthy subjects) during active movement of the affected hand. In contrast, patients with a poor motor outcome show bilateral recruitment of motor-related brain regions when moving the affected hand [10-13]. Based on this data, a maladaptive role of the contralesional (i.e., ipsilateral) hemisphere for motor recovery after stroke has been postulated. It has been assumed that the "overactive" non-lesioned hemisphere exerts an increased inhibitory influence towards the homologous areas of the lesioned hemisphere and hampers in this way the motor recovery of the affected hand. However, the general validity of this theory is still under debate. In contrast to fMRI and PET trials [10-13], TMS studies showed no clear evidence for increased excitability of the unaffected hemisphere or imbalanced interhemispheric inhibition. Moreover, no differences were detected between the unaffected hemisphere and healthy brains [14]. Furthermore, recent EEGTMS studies provide contrasting findings with regard to interhemispheric interactions in chronic stroke cohorts. One study detected increased TMS-evoked interhemispheric beta coherence during ipsilesional M1 stimulation. This was associated with reduced intracortical inhibition within both the ipsi-and the contralesional hemisphere as compared to healthy subjects [15]. In contrast, another study found decreased TMS-evoked interhemispheric beta coherence during ipsilesional M1 stimulation and detected a correlation to the amount of hand motor disability [16]. Both studies have not found any relevant differences between the contralesional hemisphere in stroke patients in comparison to healthy controls. These findings indicate that the changes of neural processing following stroke are complex and not well understood.

\section{Resting motor threshold}

Over the past decades, tens of TMS-studies have investigated reorganization within the motor cortex after 
stroke as well as its relationship to hand motor recovery. We performed a comprehensive review on the resting motor threshold measure (an objective assessment of cortical excitability) and its relationship to motor rehabilitation. The resting motor threshold (rMT) is considered as the stimulus intensity that causes a "minimum motor response" in a resting muscle during single transcranial magnetic stimulation (TMS) pulses applied over the "motor hotspot" [17]. In literature, the "minimum motor response" is defined as the lowest stimulator output intensity that elicits a motor evoked potential (MEP) with a peak-to-peak amplitude of at least $50 \mu \mathrm{V}$ in at least $50 \%$ of 8,10 or 20 consecutive stimuli [17]. The "motor hotspot" is defined as the position on the scalp where the greatest amplitude and minimum latency of the motor evoked potential can be elicited [17]. A low resting motor threshold is associated with a high cortical excitability, a high resting motor threshold with a low cortical excitability. A recent review that investigated whether the rMT is a suitable biomarker for predicting post-stroke upper limb function found a correlation between rMT and upper limb motor function after stroke [18]. However, it needs still to be clarified how the rMT in either hemisphere changes in the course of motor recovery to identify potential mechanisms of functional restoration.

\section{Methods}

\section{Data source}

The PubMed research database was searched from its inception through to 31 October 2020 for studies investigating resting motor threshold as measured by TMS and motor function of both hands in stroke patients. The search terms "stroke", "transcranial magnetic stimulation" and "motor" were used. The screening was performed by one reviewer. Figure 1 illustrates the actual search strategy.

\section{Study selection}

Studies matching the following criteria were included: (1) study on humans, (2) diagnosis of stroke with the consequence of a hemiparesis/hemiplegia, (3) assessment of motor function of both the affected and the non-affected hand, (4) assessment of resting motor threshold of the ipsilesional and/or contralesional hemisphere, (5) prospective study and (6) more than four patients included. The appropriate studies were included, regardless of study design used (interventional-observational, crossover-longitudinal, different number of groups).

\section{Data extraction}

The primary data extracted from the selected publications were (1) the hand motor function of the affected and non-affected hand and (2) the resting motor threshold of the affected and/or the non-affected hemisphere. For longitudinal studies, the baseline data, and the data of two last follow-up evaluations were extracted. If a healthy control group was available, the resting motor threshold of the non-dominant and the dominant hemisphere was extracted for a comparison with stroke subjects. The secondary selected data were (1) subjects characteristics (number, age, gender, time since stroke, stroke etiology and location), (2) methodological approach (study design, interventions, evaluations scheduling) and assessments (targeted muscle, stimulator and coil type, hand motor assessment) (Tables 1, 2, 3).

\section{Hand motor function}

Table 2 summarizes data on hand motor function of the affected and the non-affected hand. In case a study provided more than one hand motor function assessment, we selected those involving motor activities of daily living (e.g., Flugl-Meyer assessment or Wolf Motor Function Test) for our analysis. To account for differences in hand motor assessments used across studies, a laterality quotient was calculated for each study. The laterality quotient was calculated as follows: $\left(\frac{\text { Non-affected Hand-affected Hand }}{\text { Non-affected Hand }+ \text { affected Hand }}\right) * 100$. The laterality quotient varies between 0 and \pm 100 . The greater the laterality differences, the stronger the hand motor disability. Depending on the test used, motor impairment of the affected hand is associated with either a positive (e.g., Wolf Motor Function Test) or a negative value (e.g., Nine Hole Peg Test). To account for these differences, absolute values of the laterality quotient were used for the analysis of hand motor function.

\section{Resting motor threshold}

Table 3 summarizes data on resting motor threshold of the ipsilesional (non-dominant) and the contralesional (dominant) hemisphere. If the MEP was not evocable, rMT was set to 100. If data for both hemispheres were available, we calculated laterality quotients for the resting motor threshold as: $\left(\frac{\text { Contralesional hemisphere-ipsilesional hemisphere }}{\text { contralesional hemisphere+ipsilesional hemisphere }}\right) * 100 \quad$ for stroke patients, and as: $\left(\frac{\text { Dominant hemisphere-non-dominant hemsiphere }}{\text { Dominant hemisphere+non-dominant hemisphere }}\right) * 100 \quad$ for healthy controls. Negative values are associated with a between-hemispheric imbalance towards the contralesional (dominant) hemisphere, positive values with a between-hemispheric imbalance towards the lesioned (non-dominant) hemisphere.

Data synthesis and statistical analysis

Data was analyzed using SPSS Statistic 21 (IBM Corporation, USA). "Post-pre" differences between baseline and 


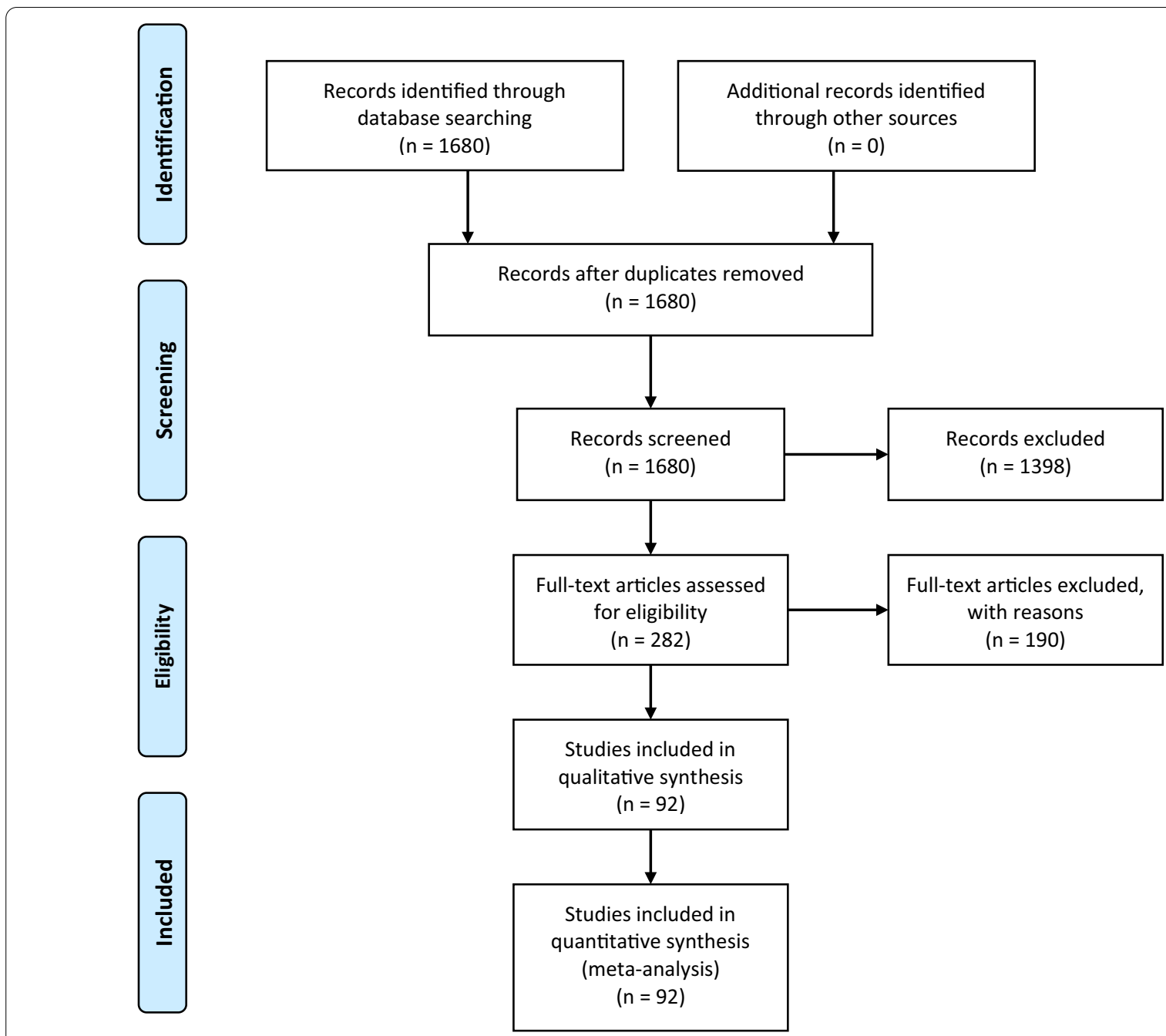

Fig. 1 Summary of literature search results based on PRISMA guidelines

first follow-up, as well as baseline and second follow up were calculated for longitudinal data of stroke patients. Furthermore, differences between rMT in stroke patients and healthy controls were calculated for studies that included healthy control group. Pearson correlations were calculated between:

(1) The amount of the hand motor impairment (expressed as laterality quotient of the hand motor function) and

(a) The ipsilesional resting motor threshold,

(b) The contralesional resting motor threshold,

(c) the between-hemispheric imbalance of resting motor threshold (expressed as laterality quotient of the resting motor thresholds).
(2) The amount of hand motor recovery (expressed as baseline-follow-up changes of laterality quotient of the hand motor function) and

(a) The baseline-follow-ups changes of the ipsilesional resting motor threshold,

(b) The baseline-follow-ups changes of the contralesional resting motor threshold,

(c) The baseline-follow-ups changes of the between-hemispheric imbalance of resting motor thresholds.

(3) (a) The ipsilesional resting motor threshold, (b) the contralesional resting motor threshold and (c) the between-hemispheric imbalance of resting motor thresholds. 


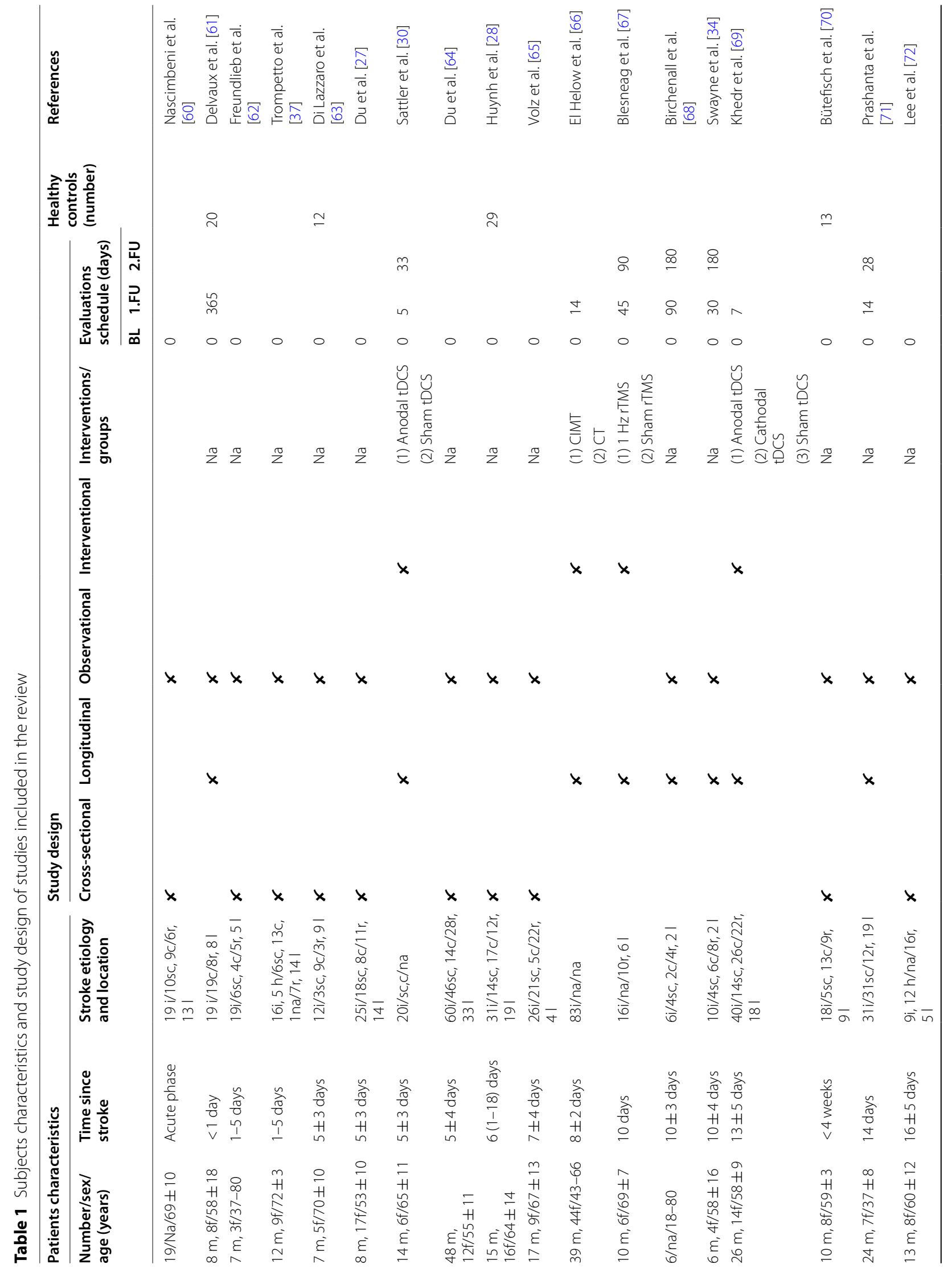




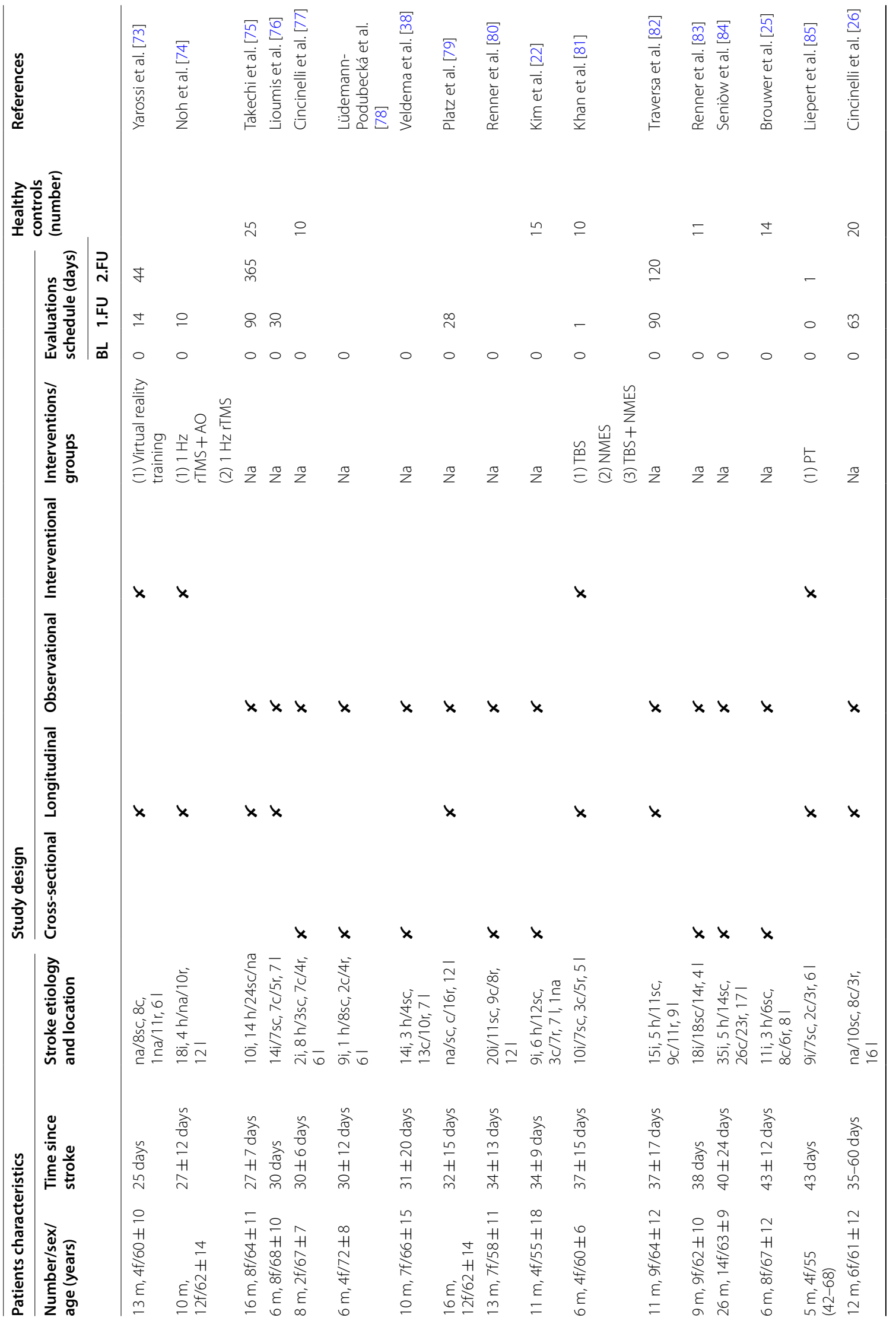




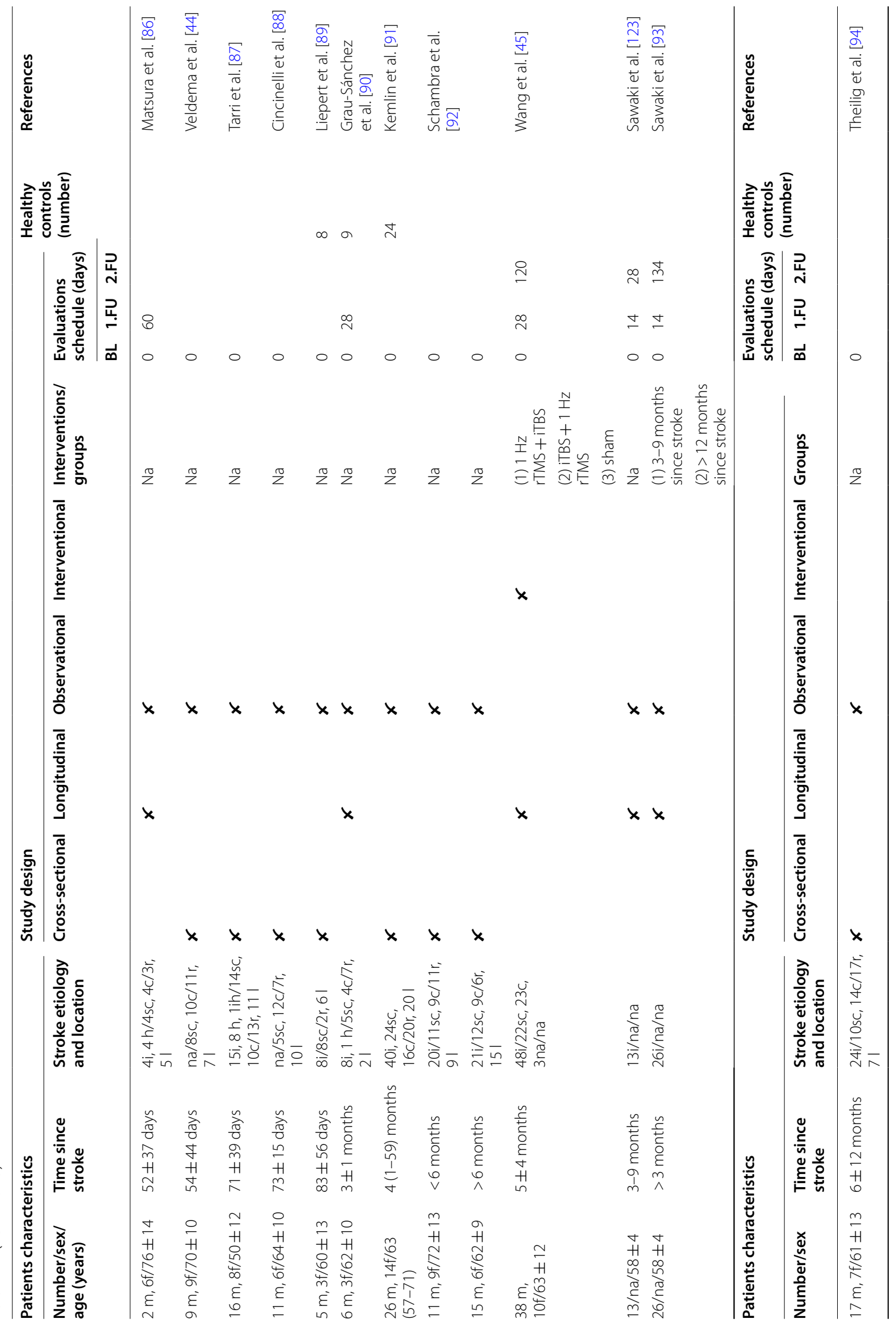




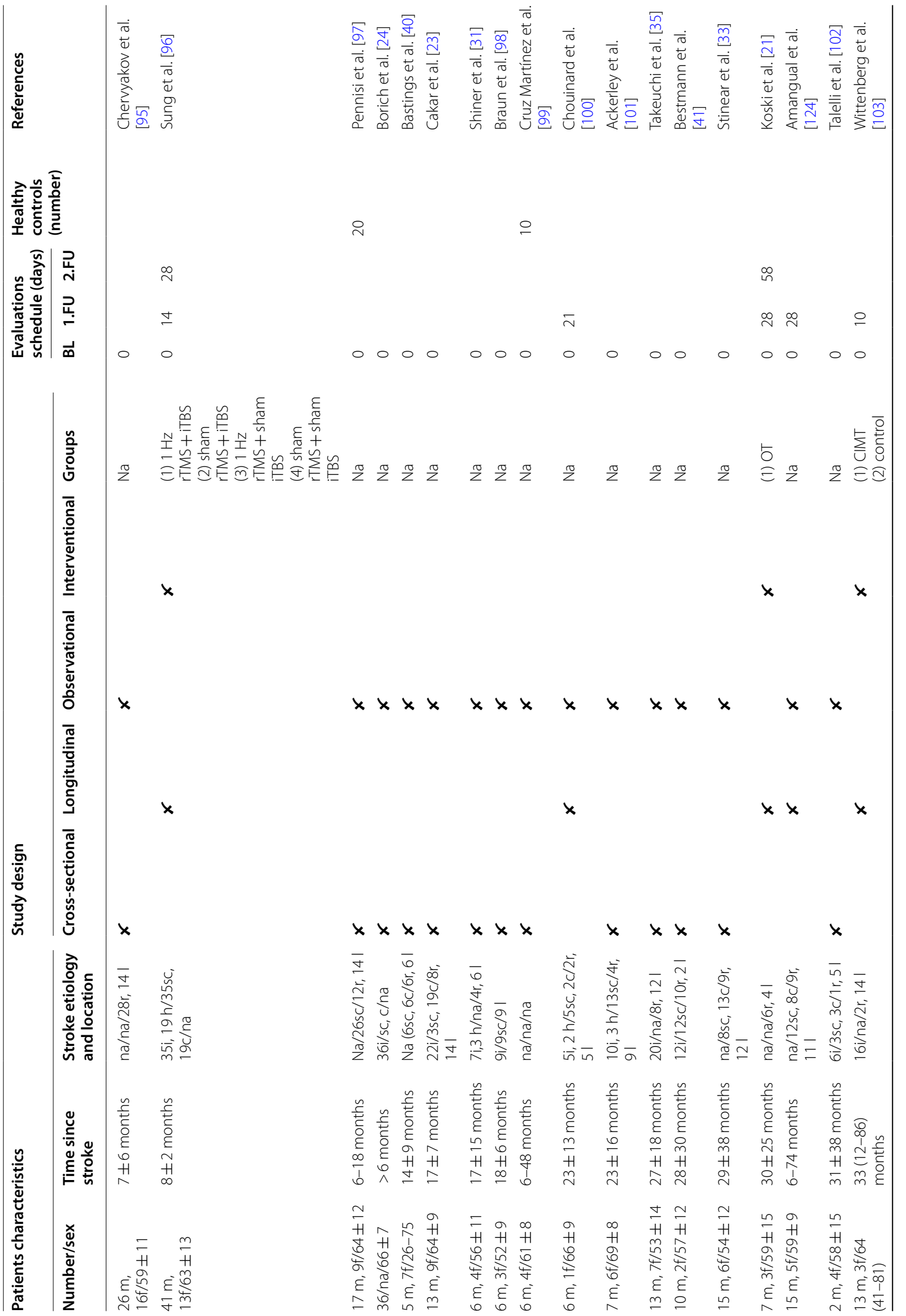




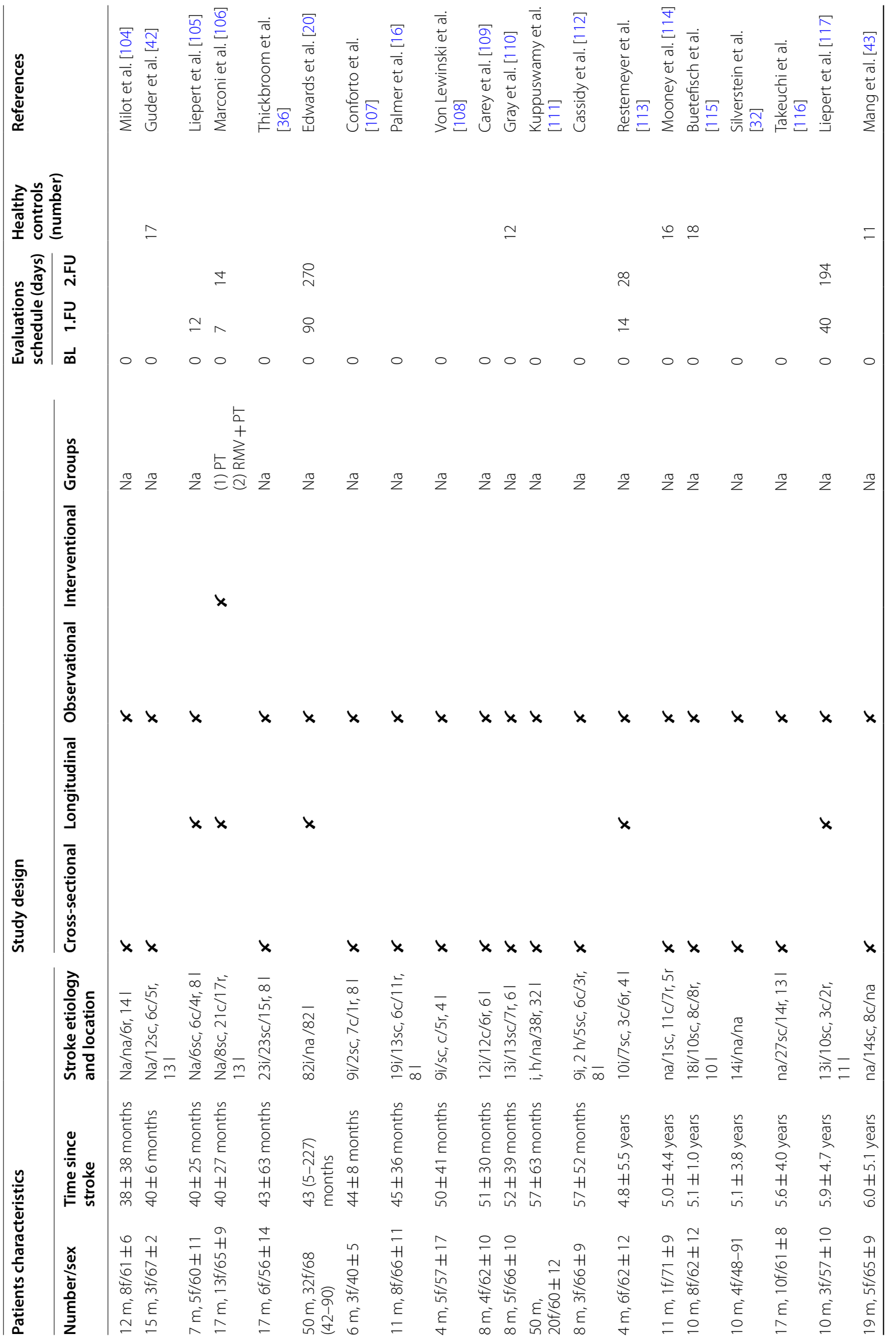




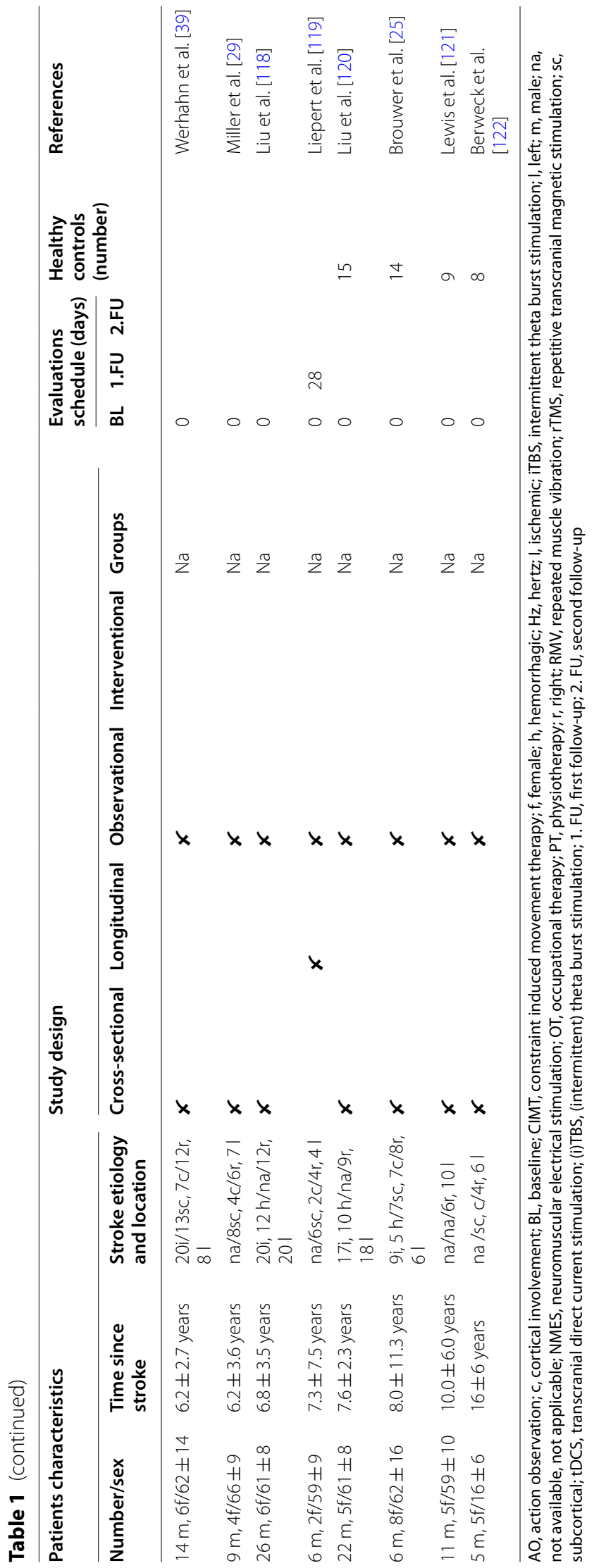




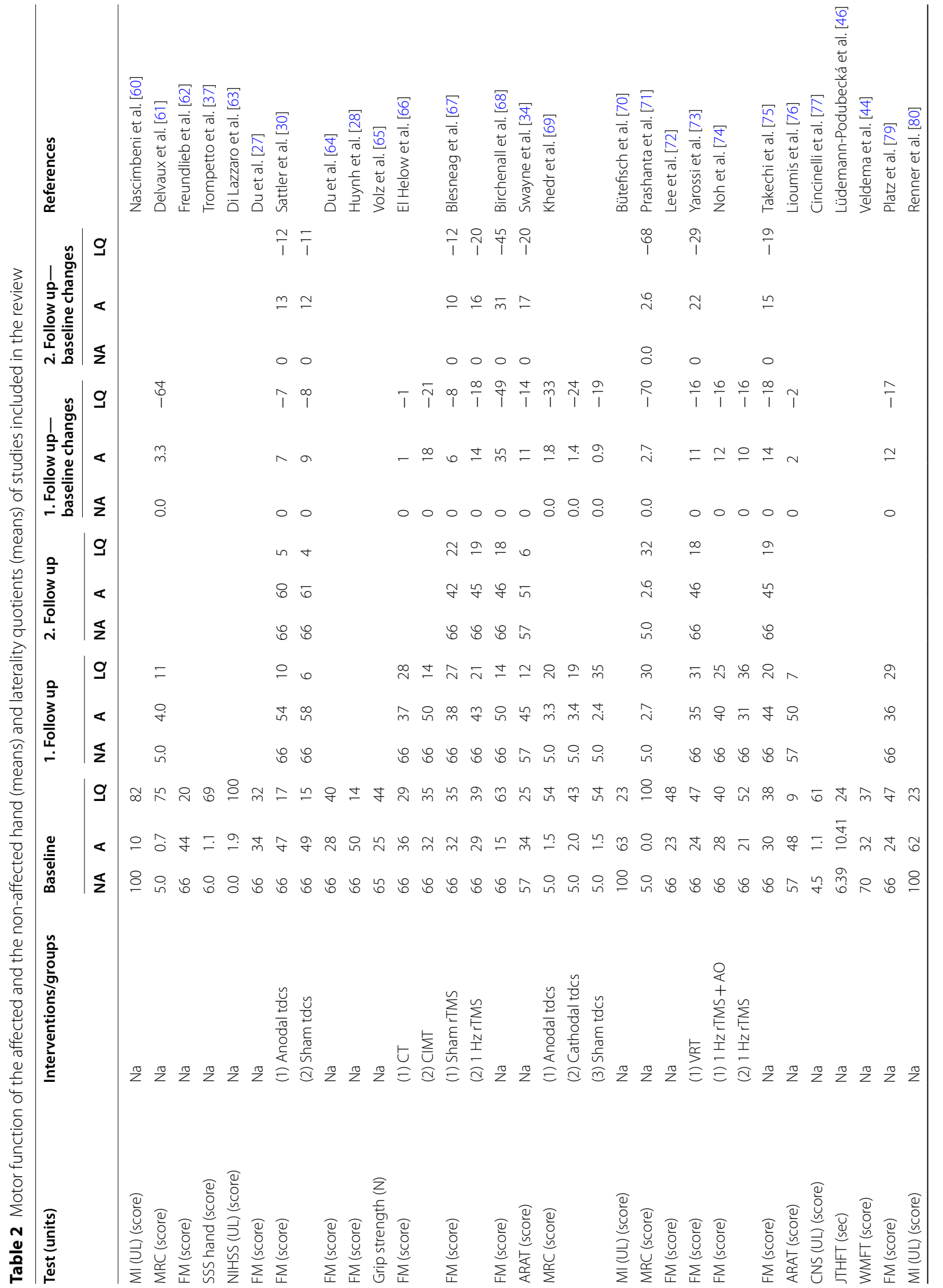




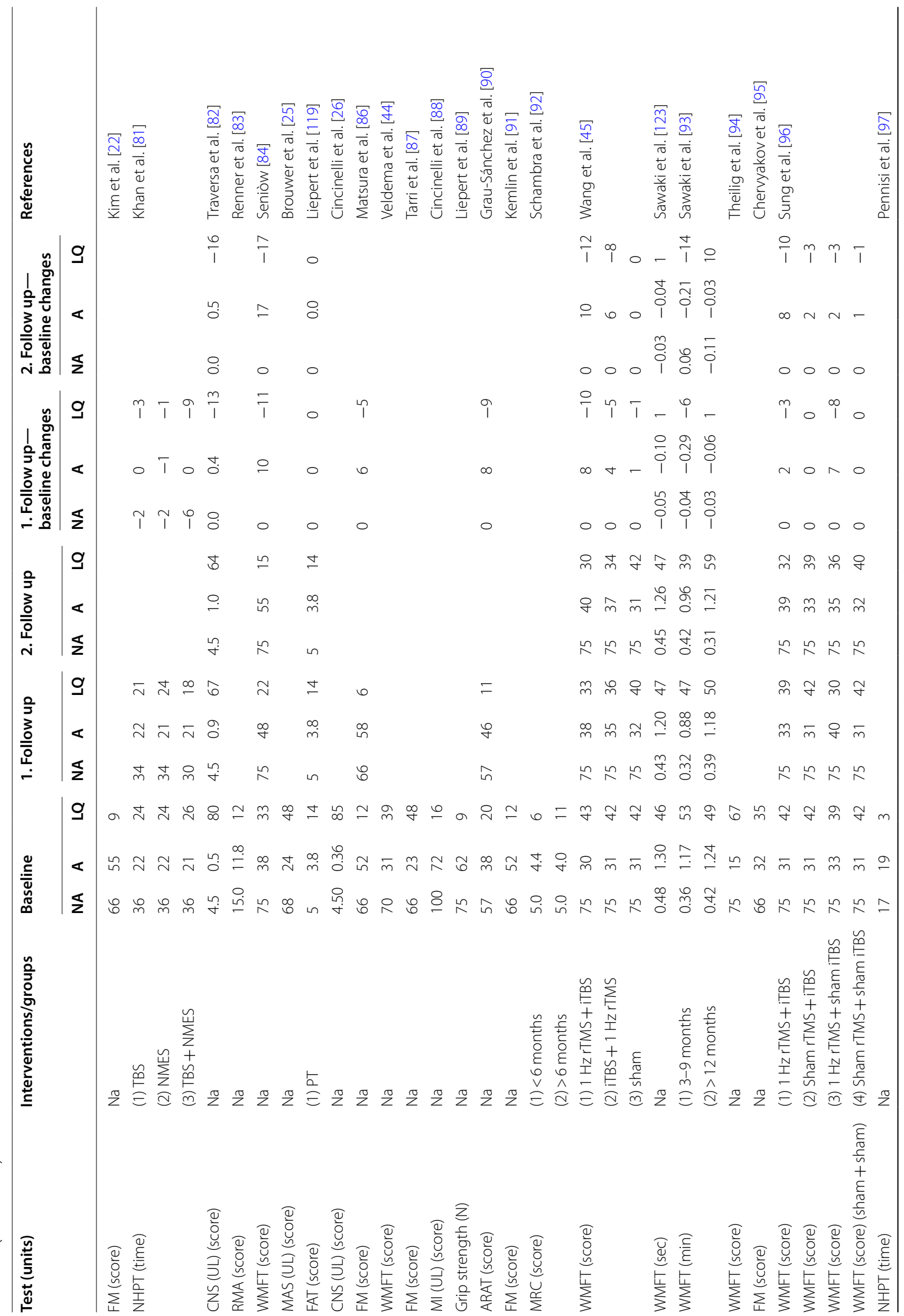




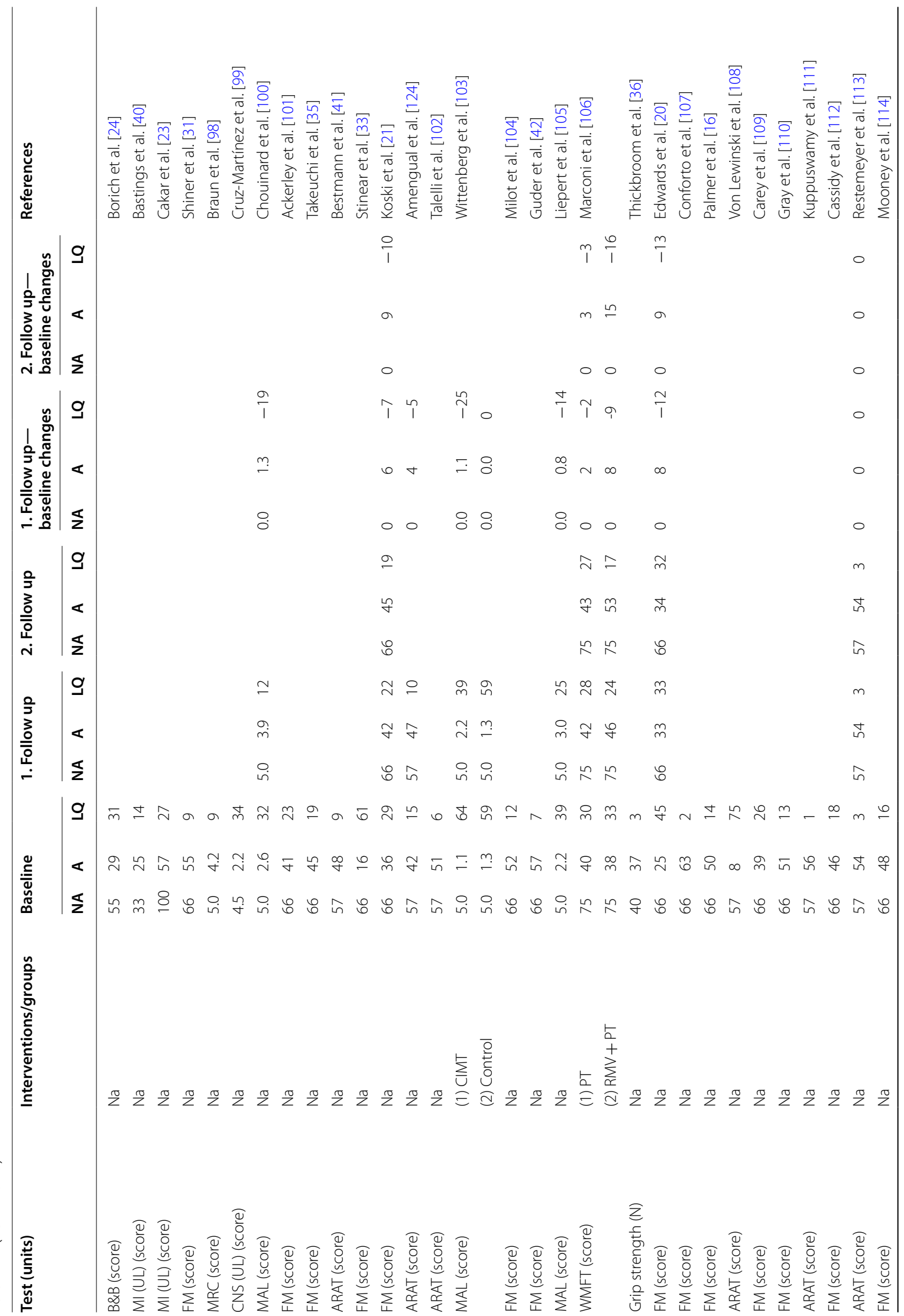




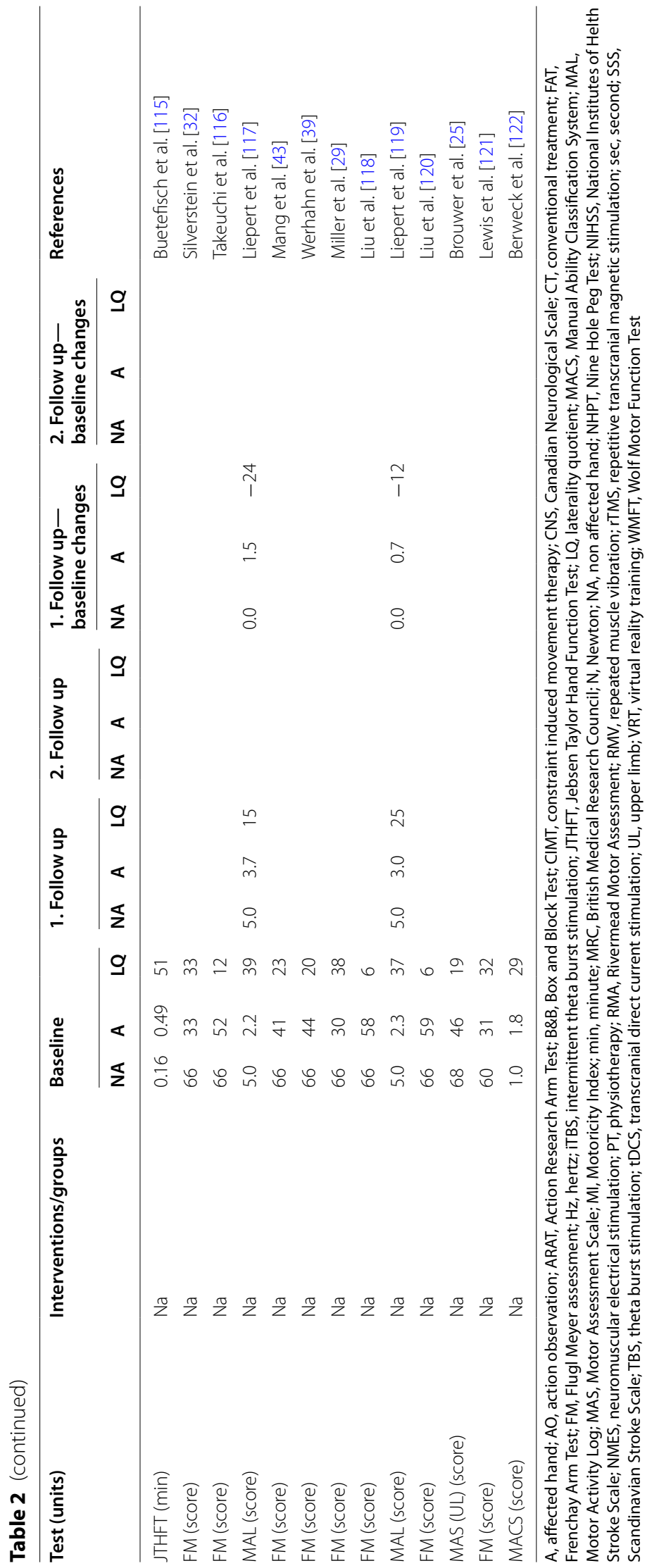




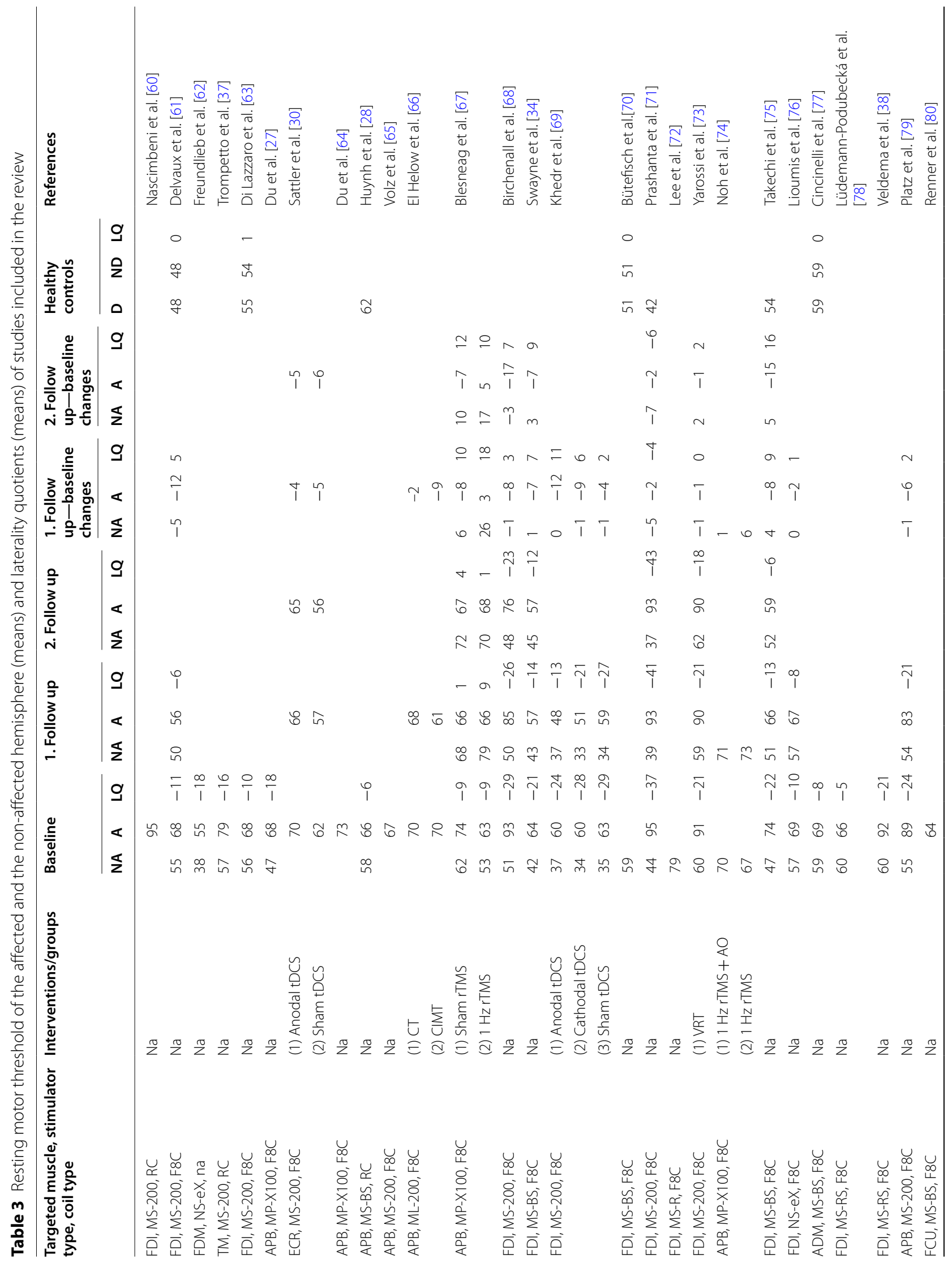




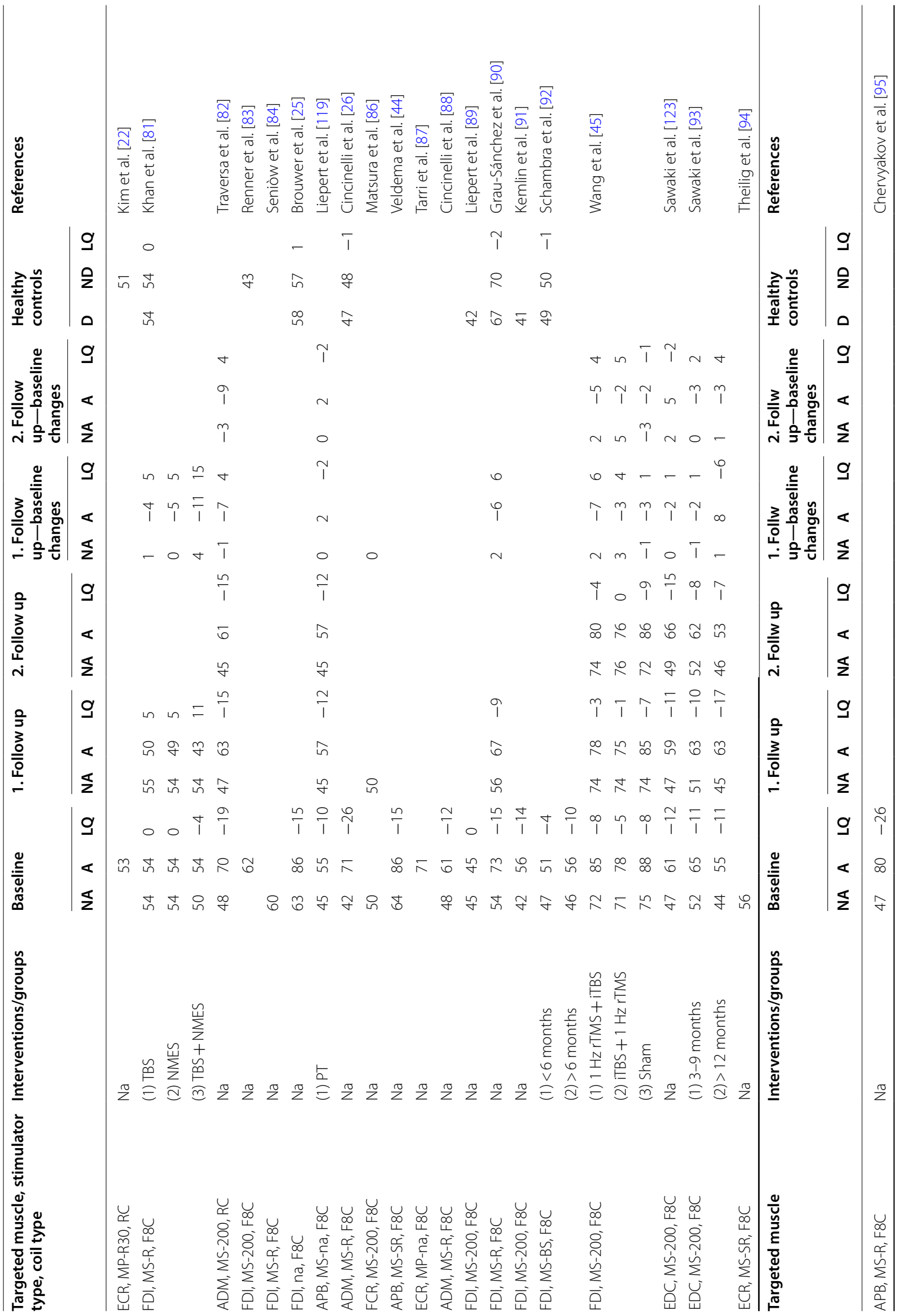




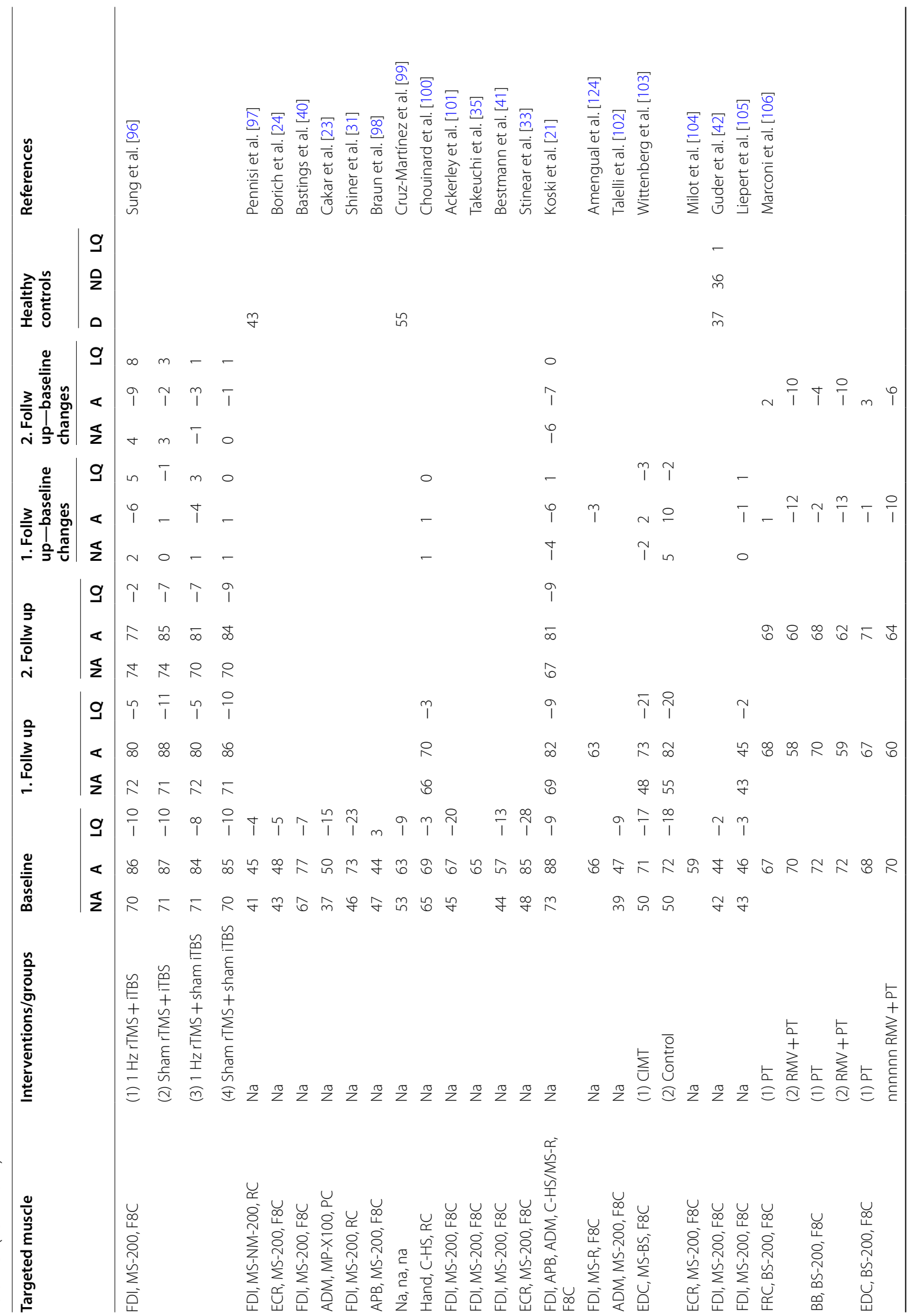




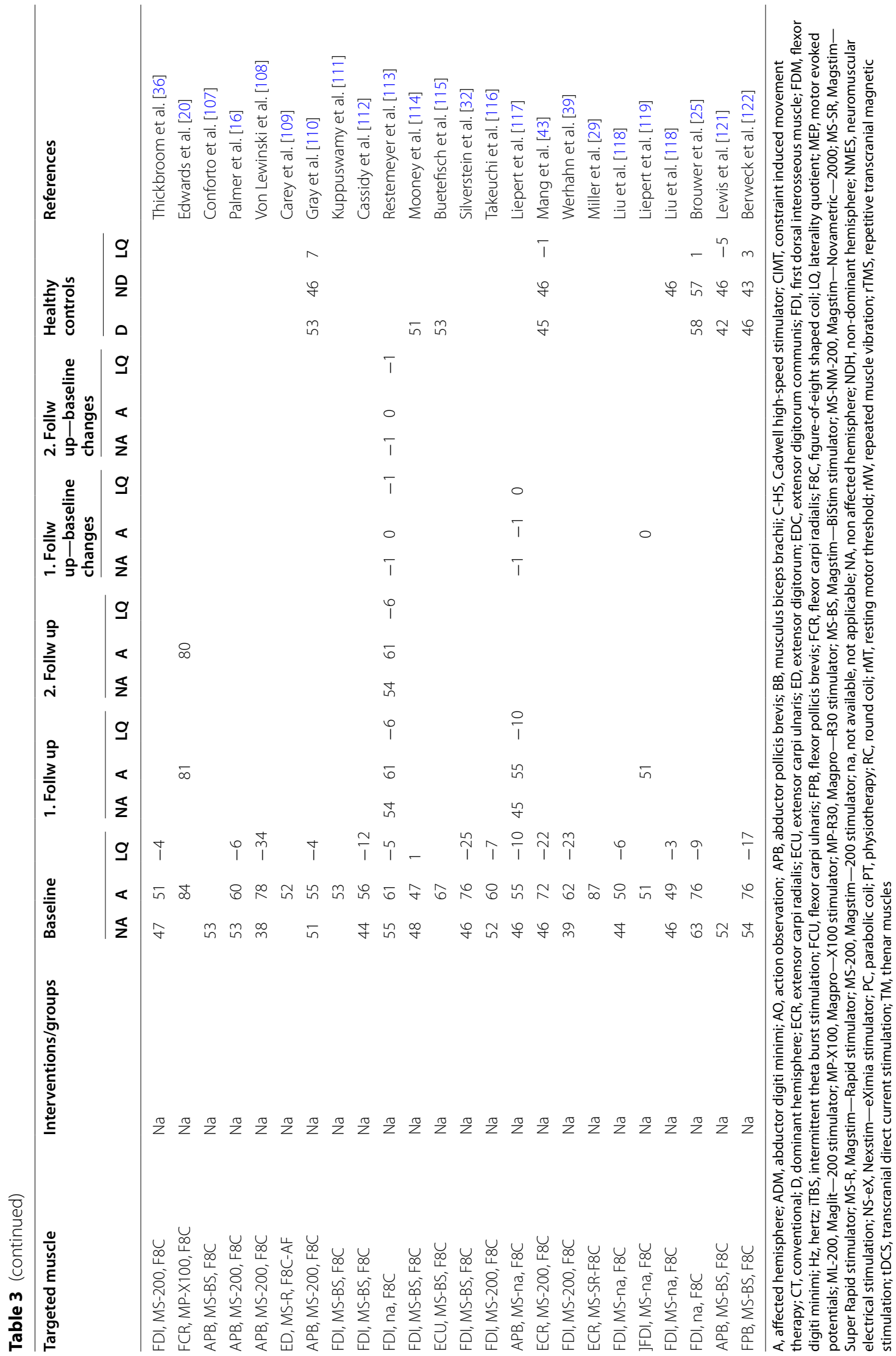


R-Values $\geq 0.3$ and $p$-values $\leq 0.05$ are considered to be statistically relevant [19].

\section{Results}

We identified 92 studies that matched our inclusion criteria. The studies show large variability of methods, participants, and results.

\section{Methods \\ Study design}

57 studies have a cross-sectional observational study design. The remaining 35 studies were either observational (21 studies) or interventional randomized (10 studies) or interventional non-randomized (4 studies) longitudinal trials that investigated hand motor function and cortical excitability for up to one year. 25 studies included a healthy control group for resting motor threshold comparison. Table 1 illustrates study design of studies enrolled.

\section{Hand motor function assessments}

Overall 17 different hand motor assessments were used: Action Research Arm Test, Box and Block Test, Canadian Neurological Scale, Frenchay Arm Test, Flugl Meyer assessment, Grip strength, Jebsen Taylor Hand Function Test, Manual Ability Classification System, Motor Activity Log, Motor Assessment Scale, Motoricity Index, British Medical Research Council, Nine Hole Peg Test, National Institutes of Helth Stroke Scale, Rivermead Motor Assessment, Scandinavian Stroke Scale, Wolf Motor Function Test. Table 2 shows the overview of hand motor assessments applied.

\section{Resting motor threshold assessments}

13 different upper limb muscles were targeted to investigate resting motor threshold: abductor digiti minimi, abductor pollicis brevis, musculus biceps brachii, extensor carpi radialis, extensor carpi ulnaris, extensor digitorum, extensor digitorum communis, first dorsal interosseous muscle, flexor digiti minimi, flexor carpi ulnaris, flexor pollicis brevis, flexor carpi radialis, thenear muscles. Two studies did not specify which upper limb muscle has been targeted. Ten different stimulator types from five different manufacturers were used: Magstim 200, Magstim BiStim 200, Magstim Rapid, Magstim Super Rapid, Magstim Novamentric 2000 (MagStim Co., Withland, Dyfed, UK), Magpro X100, Magpro R30 (Mag Venture, Farum, Denmark), Maglit 200 (Dantec Dynamics Ltd, Bristol, UK), Nexstim eXimia (Nexstim Ltd, Helsinki, Finland) and Cadwell high-speed magnetic stimulator (Cadwell Inc., Kennewick, Washington, USA). Most studies used a figure-of-eight shaped coil with a double $70 \mathrm{~mm}$ winding or a round coil with a single
$90 \mathrm{~mm}$ winding. A figure-of-eight shaped coil with a double $50 \mathrm{~mm}$ [20] and $25 \mathrm{~mm}$ [21] winding, a round coil with a single $120 \mathrm{~mm}$ winding [22] and a parabolic coil type [23] were only sporadically used. A few studies did not specify the type of stimulator or coil. Table 3 shows the overview of targeted muscles as well as of stimulators and coils used.

\section{Participants}

Overall, 1978 stroke patients and 377 healthy controls were enrolled. Table 1 summarizes patients characteristics.

\section{Patient gender}

Five studies $(n=100)$ did not report data about gender of the included subjects. All remaining studies included mixed patient cohorts. Overall, 1205 males and 674 females were investigated.

\section{Time since stroke}

time since incident varied considerably among study cohorts (between $<1$ day and 16 years at mean). 14 studies $(\mathrm{n}=444)$ tested stroke subjects in the acute phase (within 2 weeks since symptom onset). 20 studies $(\mathrm{n}=353)$ included stroke patients in the subacute phase ( 2 weeks to 2 months since symptom onset). 59 studies $(\mathrm{n}=1182)$ investigated stroke subjects in the chronic phase (more than 2 months since symptom onset).

\section{Stroke etiology}

24 studies $(\mathrm{n}=498)$ did not report data about stroke etiology. 19 studies investigated mixed (ischemic and hemorrhagic) patient cohorts. The remaining 49 studies included ischemic stroke subjects only. Overall, 1345 patients with an ischemic stroke and 135 patients with a hemorrhagic stroke were enrolled.

\section{Stroke location}

24 studies $(n=662)$ did not report data about stroke location. Most remaining studies included patients with a subcortical stroke as well as patients with a cortical involvement. Overall, 772 patients with a subcortical stroke and 545 patients with a cortical involvement were investigated.

\section{Site of lesion}

Information about the site of the lesion was absent in 11 studies $(\mathrm{n}=352)$. The remaining studies included 744 right hemispheric and 881 left hemispheric stroke patients. 


\section{Motor function of the affected hand}

Table 2 summarizes mean values of hand motor function tests and their laterality quotients across studies. There was a wide spectrum of motor disability of the affected hand across studies. The laterality quotient varied between 100 (severe hand impairment) and 1 (mild hand impairment).

\section{Resting motor threshold}

Table 3 summarizes mean values of resting motor threshold and their laterality quotients across studies. Cortical excitability of the ipsilesional and the contralesional hemisphere, as well as the between-hemispheric balance varied strongly across studies.

\section{Relationships between hand motor impairment/hand motor recovery and $\mathrm{rMT}$ Ipsilesional hemisphere}

Figure 2A illustrates overall data on ipsilesional rMT in stroke subjects and non-dominant rMT in healthy controls. Figure 2B demonstrates direct comparison of ipsilesional rMT in stroke patients and non-dominant rMT in healthy controls for studies that included healthy control group. Both illustrations indicate that ipsilesional rMT is increased in most stroke patients. Significant correlations were found between ipsilesional rMT and the amount of hand motor disability at $\mathrm{BL}(\mathrm{r}=0.558, \mathrm{p}<0.001)$ and $1 \mathrm{FU}$ $(\mathrm{r}=0.359, \mathrm{p}=0.011)$ in stroke subjects. Furthermore, the amount of increase (in comparison to healthy) correlates with hand motor disability on $\mathrm{BL}(\mathrm{r}=0.587, \mathrm{p}=0.001)$ and $1 \mathrm{FU}(\mathrm{r}=0.884, \mathrm{p}=0.008)$. Thus, the higher the hand disability, the stronger the increase of ipsilesional rMT.

Longitudinal data shows a decrease of ipsilesional rMT over time in most of the studies (Fig. 2C). Significant correlations were found between changes of ipsilesional rMT and changes of hand disability from BL to 1 $\mathrm{FU}(\mathrm{r}=0.326, \mathrm{p}=0.024)$ and from BL to $2 \mathrm{FU}(\mathrm{r}=0.365$, $\mathrm{p}=0.050$ ). A favorable hand motor recovery was associated with a decrease, an unfavorable recovery with an increase of ipsilesional rMT.

\section{Contralesional hemisphere}

Figure 2A shows overall data on contralesional rMT in stroke subjects and dominant rMT in healthy controls. Figure 2B demonstrated a direct comparison of contralesional rMT in stroke patients and dominant rMT in healthy controls for studies that included healthy control groups. The illustrations indicate both an increase and a decrease of contralesional rMT in stroke subjects in comparison to healthy subjects. No significant correlations were found between contralesional rMT (or the amount of its changes in comparison to healthy) and the amount of hand motor disability on BL and both FUs.

Longitudinal data demonstrated both an increase and a decrease of contralesional rMT over time (Fig. 2C). No significant correlations were found between changes of contralesional rMT and hand motor recovery.

\section{Between-hemispheric imbalance}

Most studies show a between-hemisphere imbalance of rMT in favor of the contralesional hemisphere in stroke patients (Fig. 2A). Its amount correlates significantly with hand motor disability at baseline $(\mathrm{r}=-0.543, \mathrm{p}<0.001)$. The poorer the motor function of the affected hand, the greater the between-hemispheric imbalance to the disadvantage of the ipsilesional hemisphere. In contrast, mild hand impairment is associated with a slight interhemispheric imbalance towards the ipsilesional hemisphere.

Longitudinal data demonstrates either partial or complete recovery of between-hemispheric balance of rMT over time in most studies (Fig. 2A). However, no significant correlations to hand motor recovery were detected.

\section{Relationships between ipsilesional rMT, contralesional rMT and between-hemispheric imbalance of $r M T$}

Significant correlations were found between ipsilesional rMT and contralesional rMT at BL $(\mathrm{r}=0.627, \mathrm{p}<0.001)$, $1 \mathrm{FU}(\mathrm{r}=0.520, \mathrm{p}=0.001)$ and $2 \mathrm{FU}(\mathrm{r}=0.472, \mathrm{p}=0.031)$. The higher the ipsilesional rMT, the higher the contralesional rMT (Fig. 3).

Ipsilesional rMT correlated significantly with the laterality quotient of $\mathrm{rMT}$ at $\mathrm{BL}(\mathrm{r}=-0.527, \mathrm{p}=0.001)$ and $1 \mathrm{FU}(\mathrm{r}=-0.418, \mathrm{p}=0.011)$. The higher the ipsilesional rMT, the greater the between-hemispheric imbalance to the disadvantage of the ipsilesional hemisphere (Fig. 3).

Contralesional rTMS correlated significantly with the laterality quotient of rMT at baseline $(r=0.320$, $\mathrm{p}=0.004), 1 \mathrm{FU}(\mathrm{r}=0.546, \mathrm{p}=0.001)$ and $2 \mathrm{FU}(\mathrm{p}=0.670$, $\mathrm{r}=0.001)$. High contralesional $\mathrm{rMT}$ was associated with small between-hemispheric imbalance (Fig. 3).

(See figure on next page.)

Fig. 2 A Overall data on resting motor threshold in healthy subjects and stroke patients. Negative values of laterality quotient are associated with a between-hemispheric imbalance towards the contralesional (dominant) hemisphere, positive values with a between-hemispheric imbalance towards the lesioned (non-dominant) hemisphere; B Resting motor threshold in stoke patients in comparison to healthy controls (only for studies which included healthy control group). Positive values re associated with a higher, negative values with a lower resting motor threshold in stroke patients (in comparison to healthy controls); C Longitudinal changes of rMT in stroke patients. Positive values are associated with an increase, negative values with a decrease of resting motor threshold over time. Notes: $\mathrm{BL}=$ baseline; RMT/rMT=resting motor threshold; $\mathrm{SO}=$ stimulator output; $1 \mathrm{FU}=$ first follow-up; $2 \mathrm{FU}=$ second follow-up 
A

A RMT

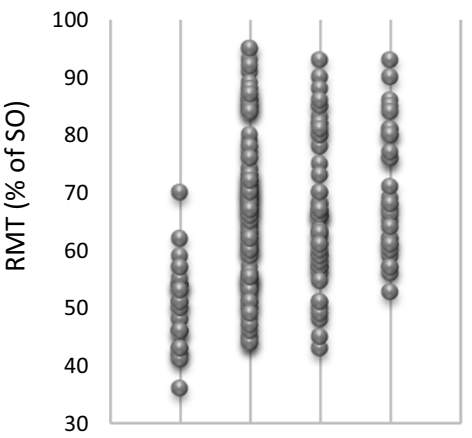

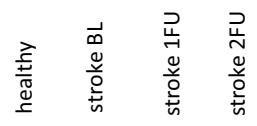

B Differencies in rMT of stroke patients and healthy controls 뜽 (ipsilesional / non-dominant hemisphere)

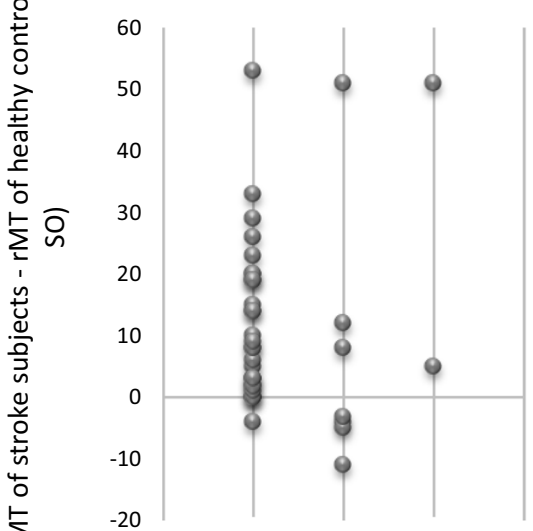

$\sum_{\leq}$

C Longitudinal changes of rMT in stroke BL $\quad 1 F U \quad 2 F U$ subjests

(ipsilesional hemisphere)

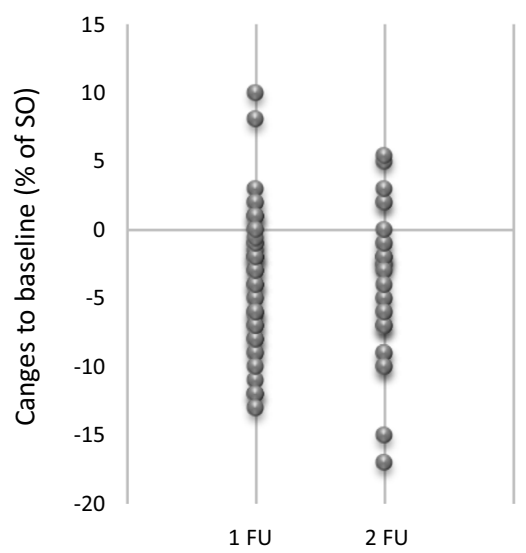

RMT

Contralesional / dominant

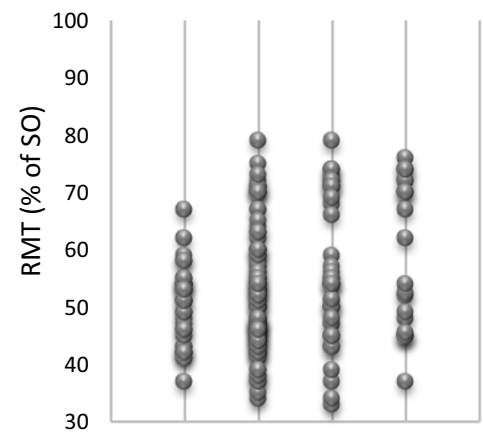

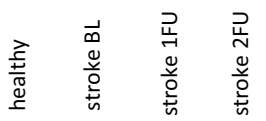

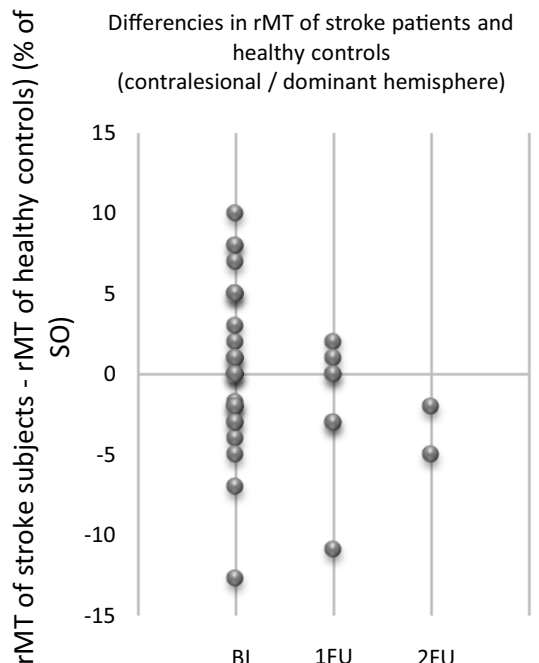

Longitudinal changes of rMT in stroke subjests

(contralesional hemisphere)

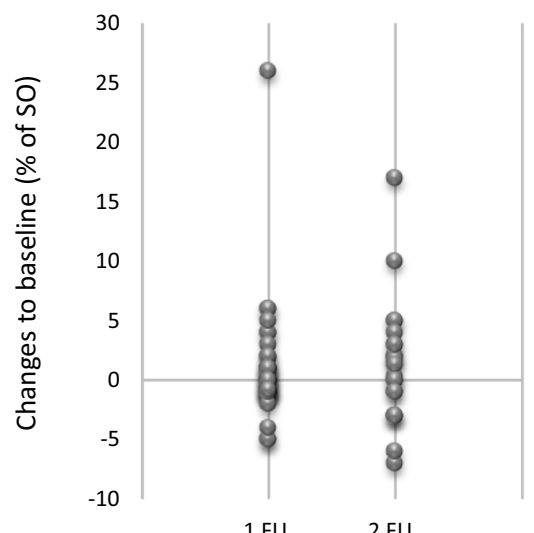

Between-hemispheric imbalances

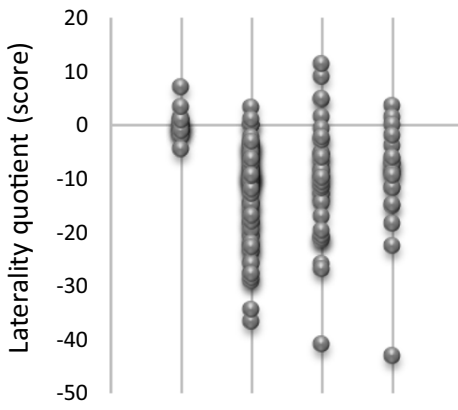

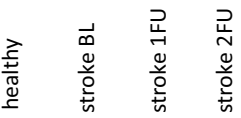

Fig. 2 (See legend on previous page.) 

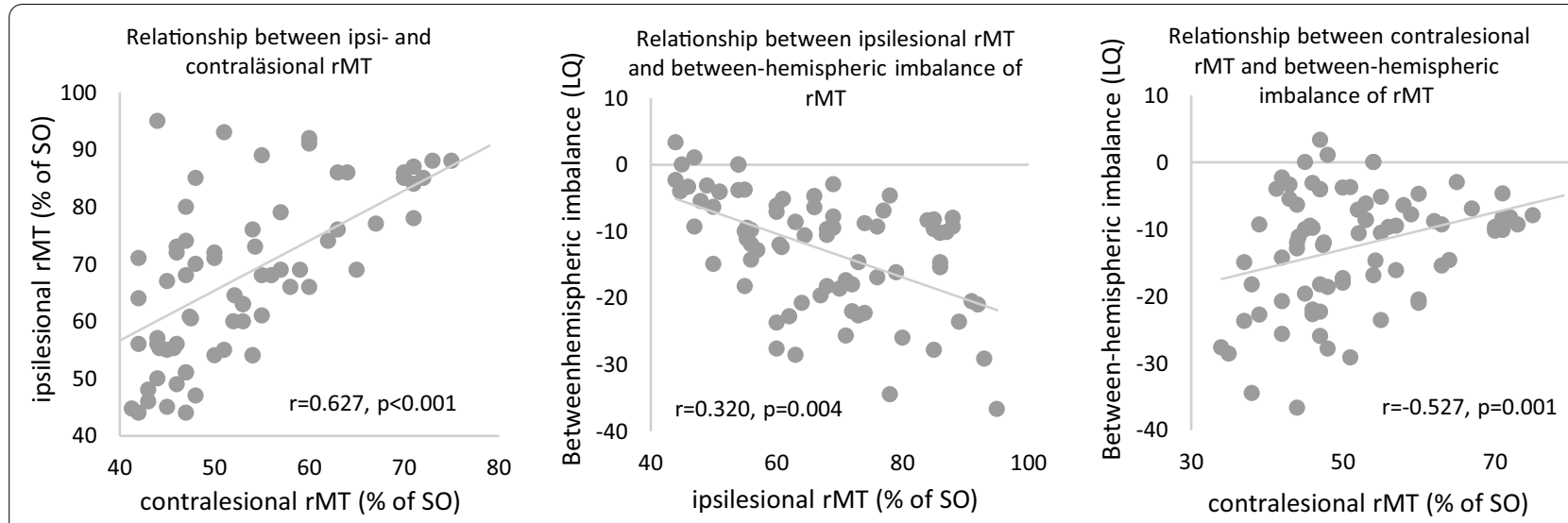

Fig. 3 Relationships between ipsilesional rMT, contralesional rMT and between-hemispheric imbalance of $\mathrm{rMT}$ at the baseline. Notes: $\mathrm{rMT}=\mathrm{resting}$ motor threshold; $\mathrm{SO}=$ stimulator output

\section{Discussion}

This systematic review aims to evaluate the neural background of hand motor disability/hand motor recovery in stroke patients, based on resting motor threshold data. In total, 92 studies including 1411 stroke subjects and 331 healthy controls were enrolled and analyzed. The available data demonstrates several relevant relationships between the neurophysiological and the behavioral data. These results may contribute to a better understanding of the neural background of motor recovery after a stroke and support the development of innovative therapies in this cohort.

\section{Cortical excitability during motor recovery after stroke}

Our data shows that severe hand motor impairment in stroke patients is associated with a suppressed cortical excitability within the ipsilesional hemisphere as well as with between-hemispheric imbalance to the disadvantage of the ipsilesional hemisphere. A favorable motor recovery is associated with an increase of ipsilesional cortical excitability and with a reduction of this betweenhemispheric imbalance. Completely recovered patients show ipsilesional cortical excitability and between-hemispheric balance comparable to healthy controls. These findings are supported by individual studies reported in our review. Nineteen studies demonstrate within their patients cohort, (1) that low ipsilesional cortical excitability is associated with poor motor function and/or (2) that favorable hand motor recovery is associated with an increase of ipsilesional cortical excitability [20, 21, 23-39]. Similarly, ten trials indicate that large betweenhemispheric imbalance to the disadvantage of the ipsilesional hemisphere is associated with severe hand motor impairment, and slight between-hemispheric imbalance in favor of the ipsilesional hemisphere is associated with mild hand impairment [21,32, 36, 38, 40-44].

With regards to the contralesional hemisphere, our data reveals both higher and lower cortical excitability in stroke patients in comparison to healthy subjects. Nonetheless, the correlation analyses show no significant link to hand motor impairment/hand motor recovery. However, three of the studies (included in our review) found significant relationships in this regard [24, 34, 45]. On the one hand, severely impaired patients in the acute phase (10 days after symptom onset) showed an increase of cortical excitability in both the contra- and the ipsilesional hemisphere, in the course of hand motor recovery [34]. On the other hand, moderately impaired patients in the chronic phase (5 months after the incident) demonstrated a decrease of contralesional cortical excitability over time [45]. Furthermore, chronic stroke patients (>6 months after the incident) with mild residual hand impairment showed higher contra- and ipsilesional cortical excitability in comparison to severely affected patients [24].

\section{Cortical excitability versus neuroimaging}

Figure 4 illustrates the evolution of cortical excitability in the course of hand motor recovery after stroke, as measured with resting motor threshold data. These observations receive support from a previous systematic review that investigates the neural background of stroke motor recovery with regard to the size and location of hand motor representation as measured by TMS [46].

Our findings differ somewhat from the traditional view of neural processing after stroke on the basis of fMRI and PET data [11-13]. A longitudinal fMRI study demonstrated in severely impaired patients a bilateral increase of task-related neural activation within 
applicable interventions

Facilitation of ipsilesional hemisphere

Facilitation of contralesional hemisphere

Inhibition of contralesional hemisphere

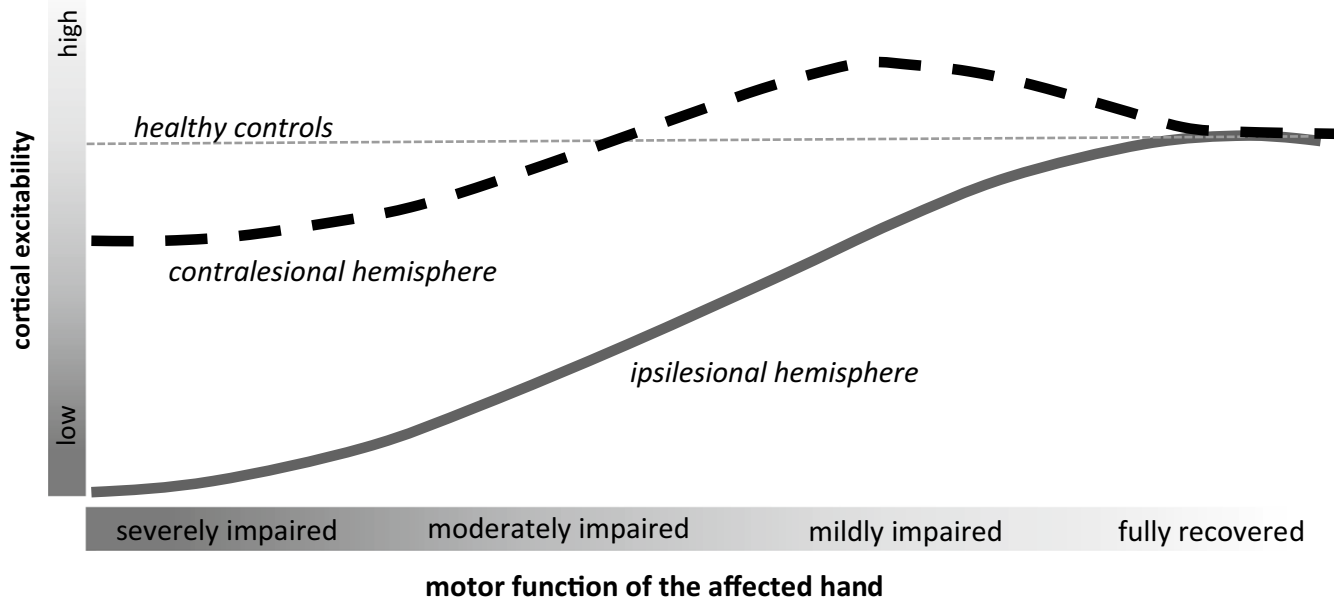

Fig. 4 Illustration of (1) changes of the cortical excitability within the ipsilesional and the contralesional hemisphere during motor recovery after a stroke as well as of (2) applicable therapy strategies

motor areas during the first two weeks after stroke. The movement-related BOLD activity in mildly impaired stroke patients did not differ from healthy subjects [11]. A cross-sectional study that recruited patients at least three months after stroke revealed similar results. Patients with less favorable hand motor recovery were more likely to recruit several motor-related brain regions over and above those recruited in healthy controls during a hand motor task [12]. In contrast, patients with favorable hand motor recovery showed a brain activation pattern similar to that found in healthy subjects [12]. Motor outcome correlated negatively with task-related activation in various brain regions, such as supplementary motor area, cingulate motor area, premotor cortex, posterior parietal cortex, and cerebellum of both ipsilateral and contralateral hemispheres [12]. In accordance with this data, a PET study demonstrated a significant increase of cerebral blood flow in several brain regions of both the contralateral and ipsilateral hemispheres (primary sensorimotor cortex, cerebellar hemispheres, insular cortex, inferior parietal, and premotor cortices) when stroke survivors moved their affected hand [13]. In contrast, active movement of the non-affected hand was associated with a significant increase of regional cerebral blood flow within the contralateral primary sensorimotor cortex and the ipsilateral cerebellar hemisphere [13]. Taken together fMRI and PET data showed a profound lateralization of neural activation within motor areas of the contralateral hemisphere in healthy subjects moving one hand. Similar brain activation patterns were found in stroke subjects moving a mildly impaired hand. Severe hand motor impairment was associated with increased neural activation within both the contralesional and ipsilesional hemispheres, which deceased over time when motor recovery proceeded. Up to now, it is still not clear if the increased compensatory recruitment of intact brain regions is an effective strategy to overcome motor impairment. A stroke incident activates a cascade of cellular and molecular processes within the peri-lesional tissue and remote brain regions [47]. Initial loss of functional and structural integrity of neural networks is followed by sprouting of axons and dendrites and formation of new synapses. The "rewiring" of neurons is expected to compensate for the stroke-induced loos of brain tissue [48]. However, aging-related decline of neural processing, such as dysfunctional activation spreading [49, $50]$ or poor network segregation $[51,52]$ may interfere with an efficient reorganization of the neural network. Elderly people, for example, show less segregated functional networks in comparison to young elderly. Multiple studies indicate the existence of multiple segregated functional networks within the human brain that exhibit correlated activity and are assumed to be functionally connected [53]. Young adults demonstrate quite dense connections within these functional networks and more sparse connections between different networks. In contrast, elderly people show weaker functional connectivity within the same functional network but stronger 
functional connectivity between regions belonging to different networks [52]. This phenomenon may be the reason for the increase recruitment of contralesional brain regions after stroke. It has been repeatedly demonstrated that a less segregated brain network is associated with worse motor and cognitive performance, independent of age $[51,52]$. An important and potentially causal role in this context plays the brain's major inhibitory neurotransmitter, gamma aminobutyric acid (GABA). Present data demonstrates reduced GABA levels in elderly people, which is correlated with both less segregated sensorimotor networks and worse sensorimotor performance in comparison to young adults [51]. The GABAeric system in particular plays a crucial role during the repair phase of stroke [54]. Another cause of extensive network activation in stroke patients may be dysfunctional activation and deactivation of specific brain areas as a result of aging. Young adults show task-related activation (increase of signal) in specific brain regions, and simultaneously deactivation (decrease of signal) in other areas as detected by PET and fMRI $[49,50]$. Interestingly, consistent deactivation patterns (within large areas of the lateral parietal cortex, medial parietal, and medial frontal cortex) can be observed across a wide range of tasks and stimulus modalities [50, 55]. A hypothesis suggests that these regions constitute a "default network" which is active when a person is not focused on the outside world, e.g., during remembering, thinking about the future, and mind wandering $[50,56]$. Elderly people show in comparison to young adults an increased spread of activation within the "task-positive areas" but a reduced spread deactivation within the "task-negative network" [49]. Such changes are typically explained as upregulation of resources, or alternatively as the reduced suppression of distracting mental processes.

In accordance with our findings, some reviews on this topic question the general validity of the simplified interhemispheric competition model-which posits that suppressing the excitability of the contralesional hemisphere will enhance recovery by reducing interhemispheric inhibition of the stroke hemisphere $[57,58]$. An earlier review, for example, analyzed the proposed mechanisms of synaptic and functional reorganization after stroke and suggests a bimodal balance-recovery model that links interhemispheric balancing and functional recovery to the structural reserve (i.e., remaining functional motor output) spared by the lesion [57]. Another review focused on the role of ipsilateral motor pathways during stroke recovery and its implications for non-invasive brain stimulation. Its results emphasize that contralesional M1 suppression may also reduce excitability of ipsilateral descending pathways that may be important for paretic upper limb control for some patients [58].

\section{Conclusions}

This review provides information about the relationship between hand motor function and motor cortex excitability changes within and across both hemispheres during recovery. In particular, the amount of motor cortex excitability of both hemispheres depended on the amount of hand motor function. In comparison to cortical excitability within the ipsilesional hemisphere, which was uniquely suppressed, motor cortex excitability within the contralesional hemisphere was reduced in those with severe hand dysfunction but enhanced in those with a less severe motor disability. Based on these findings, specific rehabilitation approaches may be developed to account for these differential changes in motor cortex excitability for mildly and severely affected stroke subjects. For example, more disabled patients may benefit from therapy strategies, which enhance motor cortex excitability within both hemispheres, e.g., a bilateral hand motor training. In contrast, mildly impaired patients may benefit from strategies that enhance motor cortex excitability within the ipsilesional hemisphere but suppress excitability within the contralesional hemisphere. This may be achieved by constraint induced movement therapy [59]. Also, within the context of non-invasive brain stimulation, the present set of data may be beneficial to develop a specific application of these techniques in dependence of the individual time-point and extent of hand motor recovery. Figure 4 illustrates how inhibitory or facilitatory rehabilitation techniques may be used in a specific fashion depending on the amount of motor impairment of the affected hand during recovery after stroke.

\section{Strength and limitations}

This is the first systematic review on rMT and hand motor function in stroke subjects. Thus, its results may contribute to a better understanding of the neural principles of motor recovery after stroke and support the application of appropriate therapeutical strategies. However, our analysis has limitations related to the reviewed data: i.e., the inconsistency of methods (diverse hand motor assessment scores, different targeted muscles, different types of stimulators and coils), subjects (different stroke states, etiologies, locations), and study designs (observational versus interventional studies, different followup timings). This may hamper the interpretation of the results.

\section{Abbreviations}

BOLD: Blood-oxygen-level-dependent; BL: Baseline; (f)MRI: (Functional) magnetic resonance imaging; GABA: Gamma aminobutyric acid; MEP: Motor evoked potential; Mm: Millimeter; M1: Primary motor cortex; PET: Positron 
emission tomography; RMT/rMT: Resting motor threshold; (r)TMS: (Repetitive) transcranial magnetic stimulation; $\mu \mathrm{V}$ : Microvolt; $1 \mathrm{FU}$ : First follow-up; $2 \mathrm{FU}$ : second follow-up.

\section{Acknowledgements}

We acknowledge support by the Open Access Publishing Fund of the University of Tübingen.

\section{Authors' contributions}

$J V$, DN and AG concepted and designed the study. JV performed the acquisition, analysis and interpretation of the data and wrote the first version of the manuscript. DN and AG contributed to data interpretation and reviewed the manuscript. All authors read and approved the final manuscript.

\section{Funding}

This research received no specific grant from any funding agency in the public, commercial, or not-for-profit sectors.

\section{Availability of data and materials}

The datasets generated during and/or analyzed during the current study are available from the corresponding author on reasonable request.

\section{Declarations}

\section{Ethical approval and consent to participate}

Not applicable.

\section{Consent for publication}

Not applicable.

\section{Competing interests}

The authors declare that there is no conflict of interest.

\begin{abstract}
Author details
${ }^{1}$ Institute for Neuromodulation and Neurotechnology, Department of Neurosurgery and Neurotechnology, University Hospital and University of Tübingen, Otfried-Mueller-Str.45, 72076 Tübingen, Germany. ${ }^{2}$ Department of Neurology, VAMED Hospital Kipfenberg, Konrad-Regler-Straße 1, 85110 Kipfenberg, Germany.
\end{abstract}

Received: 24 June 2021 Accepted: 13 October 2021

Published online: 03 November 2021

\section{References}

1. Virani SS, Alonso A, Aparicio HJ, Benjamin EJ, Bittencourt MS, Callaway CW, Carson AP, Chamberlain AM, Cheng S, Delling FN, et al. Heart disease and stroke statistics-2021 update: a report from the American Heart Association. American Heart Association Council on Epidemiology and Prevention Statistics Committee and Stroke Statistics Subcommittee. Circulation. 2021;143:e254-743.

2. Kolominsky-Rabas PL, Weber M, Gefeller O, Neundoerfer B, Heuschmann PU. Epidemiology of ischemic stroke subtypes according to TOAST criteria: incidence, recurrence, and long-term survival in ischemic stroke subtypes: a population-based study. Stroke. 2001;32:2735-40

3. Feigin VL, Lawes CM, Bennett DA, Anderson CS. Stroke epidemiology: a review of population-based studies of incidence, prevalence, and case-fatality in the late 20th century. Lancet Neurol. 2003;2:43-53.

4. Grefkes C, Fink GR. Recovery from stroke: current concepts and future perspectives. Neurol Res Pract. 2020;2:17

5. Rehme AK, Eickhoff SB, Rottschy C, Fink GR, Grefkes C. Activation likelihood estimation meta-analysis of motor-related neural activity after stroke. Neuroimage. 2012;59:2771-82.

6. Kinsbourne M. Hemi-neglect and hemisphere rivalry. Adv Neurol. 1977;18:41-9.

7. Zhang Y, Hua Y, Bai Y. Applications of functional magnetic resonance imaging in determining the pathophysiological mechanisms and rehabilitation of spatial neglect. Front Neurol. 2020;11:548568.
8. Grefkes C, Eickhoff SB, Nowak DA, Dafotakis M, Fink GR. Dynamic intra- and interhemispheric interactions during unilateral and bilateral hand movements assessed with $\mathrm{FMRI}$ and DCM. Neuroimage. 2008:41:1382-94.

9. Nowak DA, Grefkes C, Ameli M, Fink GR. Interhemispheric competition after stroke: brain stimulation to enhance recovery of function of the affected hand. Neurorehabil Neural Repair. 2009;23:641-56.

10. Grefkes C, Fink GR. Reorganization of cerebral networks after stroke: new insights from neuroimaging with connectivity approaches. Brain. 2011;134:1264-76.

11. Rehme AK, Fink GR, von Cramon DY, Grefkes C. The role of the contralesional motor cortex for motor recovery in the early days after stroke assessed with longitudinal FMRI. Cereb Cortex. 2011;21:756-68.

12. Ward NS, Brown MM, Thompson AJ, Frackowiak RS. Neural correlates of outcome after stroke: a cross-sectional fMRI study. Brain. 2003;126:1430-48.

13. Chollet F, DiPiero V, Wise RJ, Brooks DJ, Dolan RJ, Frackowiak RS. The functional anatomy of motor recovery after stroke in humans: a study with positron emission tomography. Ann Neurol. 1991;29:63-71.

14. McDonnell MN, Stinear CM. TMS measures of motor cortex function after stroke: a meta-analysis. Brain Stimul. 2017;10:721-34.

15. Borich MR, Wheaton LA, Brodie SM, Lakhani B, Boyd LA. Evaluating interhemispheric cortical responses to transcranial magnetic stimulation in chronic stroke: a TMS-EEG investigation. Neurosci Lett. 2016;618:25-30.

16. Palmer JA, Wheaton LA, Gray WA, da Silva SMA, Wolf SL, Borich MR. Role of interhemispheric cortical interactions in poststroke motor function. Neurorehabil Neural Repair. 2019;33:762-74.

17. Awiszus F, Feistner H. Kortikale reizschwelle. In: Siebner H, Ziemann U, editors. Das TMS-Buch. Springer: Berlin; 2007. p. 149-58.

18. Rosso C, Lamy JC. Does resting motor threshold predict motor hand recovery after stroke? Front Neurol. 2018;9:1020.

19. Schober P, Boer C, Schwarte LA. Correlation coefficients: appropriate use and interpretation. Anesth Analg. 2018;126:1763-8.

20. Edwards DJ, Cortes M, Rykman-Peltz A, Chang J, Elder J, Thickbroom G, Mariman JJ, Gerber LM, Oromendia C, Krebs HI, et al. Clinical improvement with intensive robot-assisted arm training in chronic stroke is unchanged by supplementary tDCS. Restor Neurol Neurosci. 2019;37:167-80.

21. Koski L, Mernar TJ, Dobkin BH. Immediate and long-term changes in corticomotor output in response to rehabilitation: correlation with functional improvements in chronic stroke. Neurorehabil Neural Repair. 2004;18:230-49.

22. Kim YJ, Ku J, Cho S, Cho YK, Lim T, Kang YJ. Facilitation of corticospinal excitability by virtual reality exercise following anodal transcranial direct current stimulation in healthy volunteers and subacute stroke subjects. J Neuroeng Rehabil. 2014;11:124.

23. Cakar E, Akyuz G, Durmus O, Bayman L, Yagci I, Karadag-Saygi E, Gunduz $\mathrm{OH}$. The relationships of motor-evoked potentials to hand dexterity, motor function, and spasticity in chronic stroke patients: a transcranial magnetic stimulation study. Acta Neurol Belg. 2016;116:481-7.

24. Borich MR, Neva JL, Boyd LA. Evaluation of differences in brain neurophysiology and morphometry associated with hand function in individuals with chronic stroke. Restor Neurol Neurosci. 2015;33:31-42.

25. Brouwer BJ, Schryburt-Brown K. Hand function and motor cortical output poststroke: are they related? Arch Phys Med Rehabil. 2006;87:627-34.

26. Cicinelli P, Traversa R, Rossini PM. Post-stroke reorganization of brain motor output to the hand: a 2-4 month follow-up with focal magnetic transcranial stimulation. Electroencephalogr Clin Neurophysiol. 1997;105:438-50.

27. Du J, Hu J, Hu J, Xu Q, Zhang Q, Liu L, Ma M, Xu G, Zhang Y, Liu X, et al. Aberrances of cortex excitability and connectivity underlying motor deficit in acute stroke. Neural Plast. 2018;2018:1318093.

28. Huynh W, Vucic S, Krishnan AV, Lin CS, Kiernan MC. Exploring the evolution of cortical excitability following acute stroke. Neurorehabil Neural Repair. 2016:30:244-57.

29. Miller KJ, Gallina A, Neva JL, Ivanova TD, Snow NJ, Ledwell NM, Xiao ZG, Menon C, Boyd LA, Garland SJ. Effect of repetitive transcranial magnetic stimulation combined with robot-assisted training on wrist muscle activation post-stroke. Clin Neurophysiol. 2019;130:1271-9. 
30. Sattler V, Acket B, Raposo N, Albucher JF, Thalamas C, Loubinoux I. Anodal tDCS combined with radial nerve stimulation promotes hand motor recovery in the acute phase after ischemic stroke. Neurorehabil Neural Repair. 2015;29:743-54.

31. Shiner $C T$, Tang H, Johnson BW, McNulty PA. Cortical beta oscillations and motor thresholds differ across the spectrum of post-stroke motor impairment, a preliminary MEG and TMS study. Brain Res. 2015;1629:26-37.

32. Silverstein J, Cortes M, Tsagaris KZ, Climent A, Gerber LM, Oromendia C, Fonzetti P, Ratan RR, Kitago T, lacoboni M, et al. Paired associative stimulation as a tool to assess plasticity enhancers in chronic stroke. Front Neurosci. 2019;13:792.

33. Stinear CM, Barber PA, Smale PR, Coxon JP, Fleming MK, Byblow WD. Functional potential in chronic stroke patients depends on corticospinal tract integrity. Brain. 2007;130:170-80.

34. Swayne OB, Rothwell JC, Ward NS, Greenwood RJ. Stages of motor output reorganization after hemispheric stroke suggested by longitudinal studies of cortical physiology. Cereb Cortex. 2008;18:1909-22.

35. Takeuchi N, Tada T, Chuma T, Matsuo Y, Ikoma K. Disinhibition of the premotor cortex contributes to a maladaptive change in the affected hand after stroke. Stroke. 2007;38:1551-6.

36. Thickbroom GW, Byrnes ML, Archer SA, Mastaglia FL. Motor outcome after subcortical stroke: MEPs correlate with hand strength but not dexterity. Clin Neurophysiol. 2002;113:2025-9.

37. Trompetto C, Assini A, Buccolieri A, Marchese R, Abbruzzese G. Motor recovery following stroke: a transcranial magnetic stimulation study. Clin Neurophysiol. 2000;111:1860-7.

38. Veldema J, Bösl K, Nowak DA. Motor recovery of the affected hand in subacute stroke correlates with changes of contralesional cortical hand motor representation. Neural Plast. 2017;2017:6171903.

39. Werhahn KJ, Conforto AB, Kadom N, Hallett M, Cohen LG. Contribution of the ipsilateral motor cortex to recovery after chronic stroke. Ann Neurol. 2004;54:464-72.

40. Bastings EP, Greenberg JP, Good D. Hand motor recovery after stroke: a transcranial magnetic stimulation mapping study of motor output areas and their relation to functional status. Neurorehabil Neural Repair. 2002;16:275-82.

41. Bestmann S, Swayne O, Blankenburg F, Ruff CC, Teo J, Weiskopf N, et al. The role of contralesional dorsal premotor cortex after stroke as studied with concurrent TMS-fMRI. J Neurosci. 2010;30:11926-37.

42. Guder S, Frey BM, Backhaus W, Braass H, Timmermann JE, Gerloff C, Schulz R. The influence of cortico-cerebellar structural connectivity on cortical excitability in chronic stroke. Cereb Cortex. 2020;30:1330-44.

43. Mang CS, Borich MR, Brodie SM, Brown KE, Snow NJ, Wadden KP, Boyd LA. Diffusion imaging and transcranial magnetic stimulation assessment of transcallosal pathways in chronic stroke. Clin Neurophysiol. 2015;126:1959-71.

44. Veldema J, Bösl K, Nowak DA. Cortico-spinal excitability and hand motor recovery in stroke: a longitudinal study. J Neurol. 2018;265:1071-8.

45. Wang CP, Tsai PY, Yang TF, Yang KY, Wang CC. Differential effect of conditioning sequences in coupling inhibitory/facilitatory repetitive transcranial magnetic stimulation for poststroke motor recovery. CNS Neurosci Ther. 2014;20:355-63.

46. Lüdemann-Podubecká J, Nowak DA. Mapping cortical hand motor representation using TMS: a method to assess brain plasticity and a surrogate marker for recovery of function after stroke? Neurosci Biobehav Rev. 2016;69:239-51.

47. Schallert T, Fleming SM, Leasure JL, Tillerson JL, Bland ST. CNS plasticity and assessment of forelimb sensorimotor outcome in unilateral rat models of stroke, cortical ablation, parkinsonism and spinal cord injury. Neuropharmacology. 2000;39:777-87.

48. Cramer SC. Repairing the human brain after stroke: I. Mechanisms of spontaneous recovery. Ann Neurol. 2008;63:272-87.

49. Gordon BA, Tse CY, Gratton G, Fabiani M. Spread of activation and deactivation in the brain: does age matter? Front Aging Neurosci. 2014;6:288.

50. Lustig C, Snyder AZ, Bhakta M, O'Brien KC, McAvoy M, Raichle ME, Morris JC, Buckner RL. Functional deactivations: change with age and dementia of the Alzheimer type. Proc Natl Acad Sci U S A. 2003:100:14504-9.
51. Cassady K, Gagnon H, Lalwani P, Simmonite M, Foerster B, Park D, Peltier SJ, Petrou M, Taylor SF, Weissman DH, Seidler RD, Polk TA. Sensorimotor network segregation declines with age and is linked to GABA and to sensorimotor performance. Neuroimage. 2019;186:234-44.

52. Chan MY, Park DC, Savalia NK, Petersen SE, Wig GS. Decreased segregation of brain systems across the healthy adult lifespan. Proc Natl Acad Sci U S A. 2014;111:4997-5006.

53. Buckner RL, Krienen FM, Yeo BT. Opportunities and limitations of intrinsic functional connectivity MRI. Nat Neurosci. 2013;16:832-7.

54. Hiu T, Farzampour Z, Paz JT, Wang EH, Badgely C, Olson A, Micheva KD, Wang G, Lemmens R, Tran KV, Nishiyama Y, Liang X, Hamilton SA, O'Rourke N, Smith SJ, Huguenard JR, Bliss TM, Steinberg GK. Enhanced phasic GABA inhibition during the repair phase of stroke: a novel therapeutic target. Brain. 2016;139:468-80.

55. McKiernan KA, Kaufman JN, Kucera-Thompson J, Binder JR. A parametric manipulation of factors affecting task-induced deactivation in functional neuroimaging. J Cogn Neurosci. 2003;15:394-408.

56. Raichle ME, MacLeod AM, Snyder AZ, Powers WJ, Gusnard DA, Shulman GL. A default mode of brain function. Proc Natl Acad Sci U S A. 2001;98:676-82.

57. Di Pino G, Pellegrino G, Assenza G, Capone F, Ferreri F, Formica D, Ranieri F, Tombini M, Ziemann U, Rothwell JC, et al. Modulation of brain plasticity in stroke: a novel model for neurorehabilitation. Nat Rev Neurol. 2014;10:597-608.

58. Bradnam LV, Stinear CM, Byblow WD. Ipsilateral motor pathways after stroke: implications for non-invasive brain stimulation. Front Hum Neurosci. 2013;7:184.

59. Uswatte G, Taub E. Constraint-induced movement therapy: a method for harnessing neuroplasticity to treat motor disorders. Prog Brain Res. 2013;207:379-401.

60. Nascimbeni A, Gaffuri A, Imazio P. Motor evoked potentials: prognostic value in motor recovery after stroke. Funct Neurol. 2006;21:199-203.

61. Delvaux V, Alagona G, Gérard P, De Pasqua V, Pennisi G, de Noordhout AM. Post-stroke reorganization of hand motor area: a 1-year prospective follow-up with focal transcranial magnetic stimulation. Clin Neurophysiol. 2003;114:1217-25.

62. Freundlieb N, Philipp S, Drabik A, Gerloff C, Forkert ND, Hummel FC. Ipsilesional motor area size correlates with functional recovery after stroke: a 6-month follow-up longitudinal TMS motor mapping study. Restor Neurol Neurosci. 2015;33:221-31.

63. Di Lazzaro V, Pilato F, Dileone M, Profice P, Capone F, Ranieri F, Musumeci G, Cianfoni A, Pasqualetti P, Tonali PA. Modulating cortical excitability in acute stroke: a repetitive TMS study. Clin Neurophysiol. 2008;119:715-23.

64. Du J, Yang F, Hu J, Hu J, Xu Q, Cong N, Zhang Q, Liu L, Mantini D, Zhang $Z$, et al. Effects of high- and low-frequency repetitive transcranial magnetic stimulation on motor recovery in early stroke patients: evidence from a randomized controlled trial with clinical, neurophysiological and functional imaging assessments. Neuroimage Clin. 2019;21:101620.

65. Volz LJ, Rehme AK, Michely J, Nettekoven C, Eickhoff SB, Fink GR, Grefkes C. Shaping early reorganization of neural networks promotes motor function after stroke. Cereb Cortex. 2016;26:2882-94.

66. El-Helow MR, Zamzam ML, Fathalla MM, El-Badawy MA, El Nahhas N, El-Nabil LM, Awad MR, Von Wild K. Efficacy of modified constraintinduced movement therapy in acute stroke. Eur J Phys Rehabil Med. 2015;51:371-9.

67. Blesneag AV, Slăvoacă DF, Popa L, Stan AD, Jemna N, Isai Moldovan F, Mureșanu DF. Low-frequency rTMS in patients with subacute ischemic stroke: clinical evaluation of short and long-term outcomes and neurophysiological assessment of cortical excitability. J Med Life. 2015;8:378-87.

68. Birchenall J, Térémetz M, Roca P, Lamy JC, Oppenheim C, Maier MA, Mas JL, Lamy C, Baron JC, Lindberg PG. Individual recovery profiles of manual dexterity, and relation to corticospinal lesion load and excitability after stroke -a longitudinal pilot study. Neurophysiol Clin. 2019:49:149-64.

69. Khedr EM, Shawky OA, El-Hammady DH, Rothwell JC, Darwish ES, Mostafa OM, Tohamy AM. Effect of anodal versus cathodal transcranial direct current stimulation on stroke rehabilitation: a pilot randomized controlled trial. Neurorehabil Neural Repair. 2013;27:592-601. 
70. Bütefisch CM, Netz J, Wessling M, Seitz RJ, Hömberg V. Remote changes in cortical excitability after stroke. Brain. 2003;126:470-81.

71. Prashantha DK, Sriranjini SJ, Sathyaprabha TN, Nagaraja D, Pal PK. Evaluation of the motor cortical excitability changes after ischemic stroke. Ann Indian Acad Neurol. 2013;16:394-7.

72. Lee J, Lee A, Kim H, Shin M, Yun SM, Jung Y, Chang WH, Kim YH. Different brain connectivity between responders and nonresponders to dual-mode noninvasive brain stimulation over bilateral primary motor cortices in stroke patients. Neural Plast. 2019;2019:3826495.

73. Yarossi M, Patel J, Qiu Q, Massood S, Fluet G, Merians A, Adamovich $\mathrm{S}$, Tunik $\mathrm{E}$. The association between reorganization of bilateral M1 topography and function in response to early intensive hand focused upper limb rehabilitation following stroke is dependent on ipsilesional corticospinal tract integrity. Front Neurol. 2019;10:258.

74. Noh JS, Lim JH, Choi TW, Jang SG, Pyun SB. Effects and safety of combined rTMS and action observation for recovery of function in the upper extremities in stroke patients: a randomized controlled trial. Restor Neurol Neurosci. 2019;37:219-30.

75. Takechi U, Matsunaga K, Nakanishi R, Yamanaga H, Murayama N, Mafune K, Tsuji S. Longitudinal changes of motor cortical excitability and transcallosal inhibition after subcortical stroke. Clin Neurophysiol. 2014;125:2055-69.

76. Lioumis P, Mustanoja S, Bikmullina R, Vitikainen AM, Kičić D, Salonen $\mathrm{O}$, TatlisumakT, Kaste M, Forss N, Mäkelä JP. Probing modifications of cortical excitability during stroke recovery with navigated transcranial magnetic stimulation. Top Stroke Rehabil. 2012;19:182-92.

77. Cicinelli P, Pasqualetti P, Zaccagnini M, Traversa R, Oliveri M, Rossini PM Interhemispheric asymmetries of motor cortex excitability in the postacute stroke stage: a paired-pulse transcranial magnetic stimulation study. Stroke. 2003;34:2653-8.

78. Lüdemann-Podubecká J, Bösl K, Nowak DA. Inhibition of the contralesional dorsal premotor cortex improves motor function of the affected hand following stroke. Eur J Neurol. 2016;23(4):823-30.

79. Platz T, van Kaick S, Möller L, Freund S, Winter T, Kim IH. Impairmentoriented training and adaptive motor cortex reorganisation after stroke: a fTMS study. J Neurol. 2005;252:1363-71.

80. Renner $\mathrm{Cl}$, Schubert M, Jahn M, Hummelsheim H. Intracortical excitability after repetitive hand movements is differentially affected in cortical versus subcortical strokes. J Clin Neurophysiol. 2009;26:348-57.

81. Khan FR, Chevidikunnan MF. Effectiveness of central plus peripheral stimulation (CPPS) on post stroke upper limb motor rehabilitation. Brain Inj. 2017;31:1494-500.

82. Traversa R, Cicinelli P, Oliveri M, Giuseppina Palmieri M, Filippi MM, Pasqualetti P, Rossini PM. Neurophysiological follow-up of motor cortical output in stroke patients. Clin Neurophysiol. 2000;111:1695-703.

83. Renner $\mathrm{Cl}$, Woldag $\mathrm{H}$, Atanasova R, Hummelsheim $\mathrm{H}$. Change of facilitation during voluntary bilateral hand activation after stroke. J Neurol Sci. 2005;39:25-30.

84. Seniów J, Bilik M, Leśniak M, Waldowski K, Iwański S, Członkowska A. Transcranial magnetic stimulation combined with physiotherapy in rehabilitation of poststroke hemiparesis: a randomized, double-blind, placebo-controlled study. Neurorehabil Neural Repair. 2012;26:1072-9.

85. Liepert J, Graef S, Uhde I, Leidner O, Weiller C. Training-induced changes of motor cortex representations in stroke patients. Acta Neurol Scand. 2000:101:321-6.

86. Matsuura A, Karita T, Nakada N, Fukushima S, Mori F. Correlation between changes of contralesional cortical activity and motor function recovery in patients with hemiparetic stroke. Phys Ther Res. 2017:20:28-35.

87. Tarri M, Brihmat N, Gasq D, Lepage B, Loubinoux I, De Boissezon X, Marque $P$, Castel-Lacanal E. Five-day course of paired associative stimulation fails to improve motor function in stroke patients. Ann Phys Rehabil Med. 2018;61:78-84.

88. Cicinelli P, Marconi B, Zaccagnini M, Pasqualetti P, Filippi MM. Rossini PM Imagery-induced cortical excitability changes in stroke: a transcranial magnetic stimulation study. Cereb Cortex. 2006;16:247-53.

89. Liepert J, Restemeyer C, Münchau A, Weiller C. Motor cortex excitability after thalamic infarction. Clin Neurophysiol. 2005;116:1621-7.

90. Grau-Sánchez J, Amengual JL, Rojo N, de Heras VLM, Montero J, Rubio F, Altenmüller E, Münte TF, Rodríguez-Fornells A. Plasticity in the sensorimotor cortex induced by Music-supported therapy in stroke patients: a TMS study. Front Hum Neurosci. 2013;7:494.

91. Kemlin C, Moulton E, Leder S, Houot M, Meunier S, Rosso C, Lamy JC. Redundancy among parameters describing the input-output relation of motor evoked potentials in healthy subjects and stroke patients. Front Neurol. 2019;10:535.

92. Schambra HM, Ogden RT, Martínez-Hernández IE, Lin X, Chang YB, Rahman A, Edwards DJ, Krakauer JW. The reliability of repeated TMS measures in older adults and in patients with subacute and chronic stroke. Front Cell Neurosci. 2015;9:335.

93. Sawaki L, Butler AJ, Leng X, Wassenaar PA, Mohammad YM, Blanton S, Sathian K, Nichols-Larsen DS, Wolf SL, Good DC, et al. Differential patterns of cortical reorganization following constraint-induced movement therapy during early and late period after stroke: a preliminary study. NeuroRehabilitation. 2014;35:415-26.

94. Theilig S, Podubecka J, Bösl K, Wiederer R, Nowak DA. Functional neuromuscular stimulation to improve severe hand dysfunction after stroke: does inhibitory rTMS enhance therapeutic efficiency? Exp Neurol. 2011;230:149-55.

95. Chervyakov AV, Poydasheva AG, Lyukmanov RH, Suponeva NA, Chernikova LA, Piradov MA, Ustinova KI. Effects of navigated repetitive transcranial magnetic stimulation after stroke. J Clin Neurophysiol. 2018;35:166-72.

96. Sung WH, Wang CP, Chou CL, Chen YC, Chang YC, Tsai PY. Efficacy of coupling inhibitory and facilitatory repetitive transcranial magnetic stimulation to enhance motor recovery in hemiplegic stroke patients. Stroke. 2013:44:1375-82.

97. Pennisi G, Alagona G, Rapisarda G, Nicoletti F, Costanzo E, Ferri R, Malaguarnera M, Bella R. Transcranial magnetic stimulation after pure motor stroke. Clin Neurophysiol. 2002;113:1536-43.

98. Braun C, Staudt M, Schmitt C, Preissl H, Birbaumer N, Gerloff C. Crossed cortico-spinal motor control after capsular stroke. Eur J Neurosci. 2007;25:2935-45.

99. Martínez CA, Muñoz J, Palacios F. The muscle inhibitory period by transcranial magnetic stimulation. Study in stroke patients. Electromyogr Clin Neurophysiol. 1998;38:189-92.

100. Chouinard PA, Leonard G, Paus T. Changes in effective connectivity of the primary motor cortex in stroke patients after rehabilitative therapy. Exp Neurol. 2006;201:375-87.

101. Ackerley SJ, Stinear CM, Barber PA, Byblow WD. Priming sensorimotor cortex to enhance task-specific training after subcortical stroke. Clin Neurophysiol. 2014;125:1451-8.

102. Talelli P, Greenwood RJ, Rothwell JC. Exploring Theta Burst Stimulation as an intervention to improve motor recovery in chronic stroke. Clin Neurophysiol. 2007;118:333-42.

103. Wittenberg GF, Chen R, Ishii K, Bushara KO, Eckloff S, Croarkin E, Taub E, Gerber LH, Hallett M, Cohen LG. Constraint-induced therapy in stroke: magnetic-stimulation motor maps and cerebral activation. Neurorehabil Neural Repair. 2003;17:48-57.

104. Milot MH, Spencer SJ, Chan V, Allington JP, Klein J, Chou C, PearsonFuhrhop K, Bobrow JE, Reinkensmeyer DJ, Cramer SC. Corticospinal excitability as a predictor of functional gains at the affected upper limb following robotic training in chronic stroke survivors. Neurorehabil Neural Repair. 2014;28:819-27.

105. Liepert J. Motor cortex excitability in stroke before and after constraintinduced movement therapy. Cogn Behav Neurol. 2006;19:41-7.

106. Marconi B, Filippi GM, Koch G, Giacobbe V, Pecchioli C, Versace V, Camerota F, Saraceni VM, Caltagirone C. Long-term effects on cortical excitability and motor recovery induced by repeated muscle vibration in chronic stroke patients. Neurorehabil Neural Repair. 2011;25:48-60.

107. Conforto AB, Santos RL, Farias SN, Marie SK, Mangini N, Cohen LG. Effects of somatosensory stimulation on the excitability of the unaffected hemisphere in chronic stroke patients. Clinics (Sao Paulo). 2008;63:735-40.

108. von Lewinski F, Hofer S, Kaus J, Merboldt KD, Rothkegel H, Schweizer R, Liebetanz D, Frahm J, Paulus W. Efficacy of EMG-triggered electrical arm stimulation in chronic hemiparetic stroke patients. Restor Neurol Neurosci. 2009:27:189-97.

109. Carey JR, Deng H, Gillick BT, Cassidy JM, Anderson DC, Zhang L, Thomas W. Serial treatments of primed low-frequency rTMS in stroke: 
characteristics of responders vs. nonresponders. Restor Neurol Neurosci. 2014;32:323-35.

110. Gray WA, Palmer JA, Wolf SL, Borich MR. Abnormal EEG responses to TMS during the cortical silent period are associated with hand function in chronic stroke. Neurorehabil Neural Repair. 2017;31:666-76.

111. Kuppuswamy A, Clark EV, Turner IF, Rothwell JC, Ward NS. Post-stroke fatigue: a deficit in corticomotor excitability? Brain. 2015;138:136-48.

112. Cassidy JM, Chu H, Anderson DC, Krach LE, Snow L, Kimberley TJ, Carey JR. A comparison of primed low-frequency repetitive transcranial magnetic stimulation treatments in chronic stroke. Brain Stimul. 2015:8:1074-84

113. Restemeyer C, Weiller C, Liepert J. No effect of a levodopa single dose on motor performance and motor excitability in chronic stroke. A double-blind placebo-controlled cross-over pilot study. Restor Neurol Neurosci. 2007;25:143-50.

114. Mooney RA, Ackerley SJ, Rajeswaran DK, Cirillo J, Barber PA, Stinear CM, Byblow WD. The influence of primary motor cortex inhibition on upper limb impairment and function in chronic stroke: a multimodal study. Neurorehabil Neural Repair. 2019;33:130-40.

115. Buetefisch CM, Revill KP, Haut MW, Kowalski GM, Wischnewski M, Pifer M, Belagaje SR, Nahab F, Cobia DJ, Hu X, et al. Abnormally reduced primary motor cortex output is related to impaired hand function in chronic stroke. J Neurophysiol. 2018;120:1680-94.

116. Takeuchi N, Tada T, Matsuo Y, Ikoma K. Low-frequency repetitive TMS plus anodal transcranial DCS prevents transient decline in bimanual movement induced by contralesional inhibitory rTMS after stroke. Neurorehabil Neural Repair. 2012;26:988-98.

117. Liepert J, Bauder H, Wolfgang HR, Miltner WH, Taub E, Weiller C. Treatment-induced cortical reorganization after stroke in humans. Stroke. 2000;31:1210-6.
118. Liu H, Au-Yeung SSY. Corticomotor excitability effects of peripheral nerve electrical stimulation to the paretic arm in stroke. Am J Phys Med Rehabil. 2017:96:687-93.

119. Liepert J, Haevernick K, Weiller C, Barzel A. The surround inhibition determines therapy-induced cortical reorganization. Neuroimage. 2006;32:1216-20

120. Liu H, Au-Yeung SS. Reliability of transcranial magnetic stimulation induced corticomotor excitability measurements for a hand muscle in healthy and chronic stroke subjects. J Neurol Sci. 2014:341:105-9.

121. Lewis GN, Perreault EJ. Side of lesion influences interhemispheric inhibition in subjects with post-stroke hemiparesis. Clin Neurophysiol. 2007:118:2656-63.

122. Berweck S, Walther M, Brodbeck V, Wagner N, Koerte I, Henschel V, et al. Abnormal motor cortex excitability in congenital stroke. Pediatr Res. 2008;63:84-8.

123. Sawaki L, Butler AJ, Leng X, Wassenaar PA, Mohammad YM, Blanton S, Sathian K, Nichols-Larsen DS, Wolf SL, Good DC, et al. Constraintinduced movement therapy results in increased motor map area in subjects 3 to 9 months after stroke. Neurorehabil Neural Repair. 2008;22:505-13.

124. Amengual JL, Rojo N, de Heras VHM, Marco-Pallarés J, Grau-Sánchez J, Schneider S, Vaquero L, Juncadella M, Montero J, Mohammadi B, et al. Sensorimotor plasticity after music-supported therapy in chronic stroke patients revealed by transcranial magnetic stimulation. PLOS ONE. 2013:8:e61883.

\section{Publisher's Note}

Springer Nature remains neutral with regard to jurisdictional claims in published maps and institutional affiliations.
Ready to submit your research? Choose BMC and benefit from:

- fast, convenient online submission

- thorough peer review by experienced researchers in your field

- rapid publication on acceptance

- support for research data, including large and complex data types

- gold Open Access which fosters wider collaboration and increased citations

- maximum visibility for your research: over $100 \mathrm{M}$ website views per year

At BMC, research is always in progress.

Learn more biomedcentral.com/submissions 